Research Article

\title{
Analysis of Bond Behavior of FRP-Confined Concrete Piles Based on Push-Out Test
}

\author{
Zheng-zhen Wang ${ }^{(D)}$, Wei-ming Gong ${ }^{D}$, Guo-liang Dai, and Ling-feng Liu \\ Key Laboratory for RC and PRC Structure of Education Ministry, School of Civil Engineering, Southeast University, \\ No.2 Sipailou, Nanjing, Jiangsu 210096, China
}

Correspondence should be addressed to Wei-ming Gong; 101004924@seu.edu.cn

Received 6 April 2019; Revised 21 July 2019; Accepted 30 September 2019; Published 26 February 2020

Academic Editor: Hiroshi Noguchi

Copyright (c) 2020 Zheng-zhen Wang et al. This is an open access article distributed under the Creative Commons Attribution License, which permits unrestricted use, distribution, and reproduction in any medium, provided the original work is properly cited.

\begin{abstract}
Due to the significant differences in the properties (e.g., anisotropy, elasticity modulus, and surface roughness) of fibre-reinforced polymer (FRP) and traditional pile materials, research on bond behavior between FRP tube and concrete should be conducted to ensure that they can work together properly. Push-out tests on twenty-nine GFRP-confined concrete piles were performed, the influence of bond type, slenderness ratio of FRP tube, radius-thickness ratio of FRP tube, concrete stress and concrete type on bond behavior and distribution of axial strains were studied, and simplified bond-slip constitutive models based on test results were proposed. It was found that bond type was a critical factor influencing bond behavior. A smaller radius-thickness ratio, a higher concrete stress, and the use of expansive concrete were advantageous for achieving higher bond behavior, whereas the slenderness ratio had little influence on the bond behavior. The axial strain distribution of all FRP tubes demonstrated the following rules: the upper strain was greater than the middle strain, which was larger than the lower strain, but for normal concrete specimens, the strain was linearly distributed with height, while for expanded concrete specimens, the distribution curves were polylines.
\end{abstract}

\section{Introduction}

Pile foundations have been widely used in bridge engineering and off-shore wind industry [1]. However, there are many problems associated with pile foundations made of traditional materials such as steel, concrete, and timber, especially when installed in corrosive and marine environments. For example, steel corrosion and concrete deterioration may reduce the bearing capacity of pile foundations and affect the safety of its superstructure $[2,3]$. For the past decade, there has been a continuously increasing interest in the use of composite piles to replace traditional piles. FRP-confined concrete pile is a typical type of the composite piles, which are comprised of an outer FRP tube and concrete infill. The outer FRP tube can confine the concrete in compression, keep the concrete from severe environment effects, and act as a load-carrying partner. On the other hand, the concrete can prevent local buckling of FRP tube and increase the stiffness of piles $[4,5]$.
Nevertheless, before FRP-confined concrete piles are widely accepted, research must be done on all aspects of their behavior. Bond between FRP tube and concrete is of great importance for the effectiveness of FRP-confined concrete pile because bond is the key for composite action of FRP tube and concrete [6].

Many studies have been undertaken to understand the bond behavior between FRP and concrete. Based on their tests, Larralde and Silva-Rodriguez reported that the average bond stress at failure was greater for the steel bars than for the FRP bars under the same test condition, and this conclusion was confirmed by Hao et al. [7, 8]. Pellegrino et al. found that bond behavior between FRP and concrete depends on many factors including concrete stress, bar diameter, surface treatment, and the type of adhesive layer [9-12]. Chen and Chouw investigated the effect of the interface condition on the bond between FRP tube and concrete and found that mechanically bonded interface could highly enhance the bond [13]. Katz et al. concluded 
that fine roughness of rod surface had a positive effect on high bond, whereas high temperature and cyclic loading were detrimental to bond stress [14-16]. Li et al. studied the influence of concrete strength on bond stress of FRP tube-encased concrete columns and reported that the confinement efficiency and the interfacial bond stress were low for very high stress concrete [17]. Dai et al. analyzed the effect of moisture on the initial and long-term bond behavior of FRP sheets to concrete interfaces and concluded that the effect of the concrete substrate moisture content on shortterm interfacial bond performance could be eliminated, but the interfacial bond stress degraded asymptotically with the time of being subjected to combined wet/dry and thermal cycling [18]. Zheng et al. investigated the fatigue bond performance of FRP laminate-concrete interface subjected to hygrothermal environment and found that the hygrothermal environment adversely affected the bond behavior of FRP laminate-concrete interface and the fatigue life of specimens under hygrothermal environment was significantly less than that of reference specimens without hygrothermal pretreatment [19]. Savoia et al. derived a nonlinear mode and a new bond-slip model in terms of CFRP-bonded length, CFRP-bonded width, and anchored system by the inverse analysis and the parametric study of bond-slip behavior [20, 21]. A simple but robust finite-element model and a mesoscale finite-element model using the $\mathrm{K} \& \mathrm{C}$ concrete damage model in LS-DYNA were proposed by Tao et al. and Li et al. separately to simulate the bond behavior of FRP-concrete $[22,23]$. Neto et al. identified the role of the load misalignment in the bond behavior of GFRP-concrete by numerical simulation, and it was concluded that the bond behavior significantly decreased in the case of a misaligned load pointing outward the reinforced surface, and this effect was less relevant for thick laminates when compared with thin FRP sheets [24].

It is noted that most research of FRP-concrete bond behavior is based on FRP bar or FRP sheet, and little work has previously been conducted on the bond behavior between FRP tube and concrete. Thus, in this paper, push-out tests of twenty-nine specimens were preformed to further identify the parameters that control the bond behavior between FRP tube and concrete, including bond type, slenderness ratio of FRP tube, radius-thickness ratio of FRP tube, concrete stress, and concrete type. Based on the test results, distribution and development law of axial strain of FRP tube were analysed, and simplified bond-slip constitutive models were proposed to describe the bond-slip curves of FRP-confined concrete piles.

\subsection{Test Conditions}

1.1.1. Test Setup. Push-out test, which is a good way to assess the bond behavior between FRP tube and concrete infill, was performed on all the specimens [25-27]. The test setup is shown in Figure 1. All tests were conducted on a self-made load reaction frame, which was welded by Q235 steel in the laboratory and had sufficient stiffness to ensure ignorable deformation during all tests. A hand hydraulic jack with a capacity of $300 \mathrm{kN}$ and a measuring range of $60 \mathrm{~mm}$ was used to apply vertical loads on loading plate. A $50 \mathrm{~mm}$ gap was reserved when pouring concrete inside a FRP tube. The loading plate was placed in contact with the top of the specimen where the gap was located to transfer pressure applied by the hydraulic jack on the FRP tube only, whereas the bottom of the specimen was in contact with a steel column whose diameter was less than the FRP tube leading to reaction force being applied only to the concrete.

\section{Materials and Specimens}

The parameters of the twenty-nine specimens fabricated for this study are provided in Table 1; the test variables included bond type, slenderness ratio of FRP tube, radius-thickness ratio of FRP tube, concrete strength, and concrete type. All FRP tubes were made from glass fibre-reinforced polymer (GFRP), and the properties of the GFRP are shown in Table 2.

According to the bond type, there were three types of FRP tubes, the first type was normal FRP tube, whose inner surface is smooth (Figure 2(a)); the second type was FRP tube with internal threads: the depth and spacing of internal threads were $2.5 \mathrm{~mm}$ and $10 \mathrm{~mm}$ separately and the internal threads were arranged along the entire inner surface of FRP tube (Figure 2(b)); the third type was FRP tube with shear connectors: shear connectors were made of steel nails with a length of $70 \mathrm{~mm}$, and a diameter of $3 \mathrm{~mm}$ (Figure 2(c)); the number and position of shear connectors are shown in Figure 3.

Two types of concrete (normal concrete and expansive concrete) and three different concrete strengths (C30, C50 and C60) were used in the tests, and the concrete was prepared in the laboratory. Calcium sulphoaluminate expansive agent was added into the expansive concrete, whose amount was $8 \%$ of cement weight. To measure the mechanical properties of concrete, three standard concrete test blocks of each kind of concrete strength were reserved, which would be cured for 28 days under the same condition of the specimens. The properties of concrete are demonstrated in Table 3.

2.1. Measuring Equipment and Test Method. To measure the relative slip between the FRP tube and concrete, four electronic displacement sensors and four dial gauges were installed at top surface and bottom surface of the FRP tube (each surface has two electronic displacement sensors and two dial gauges). The electronic displacement sensors were connected with the signal receiving apparatus, which could instantly display the load-displacement curves on a computer. The role of the dial gauges was to verify the correctness of test results recorded by the electronic displacement sensors.

The axial strain distribution was obtained from strain gauges mounted on the outside surface of the FRP tube (Figure 4). The BX120-4BB resistance strain gauges were used in the test, whose gauge resistance range was $120.1 \pm 0.2 \Omega$ and gauge factor was $2.08 \pm 1 \%$. The strain 

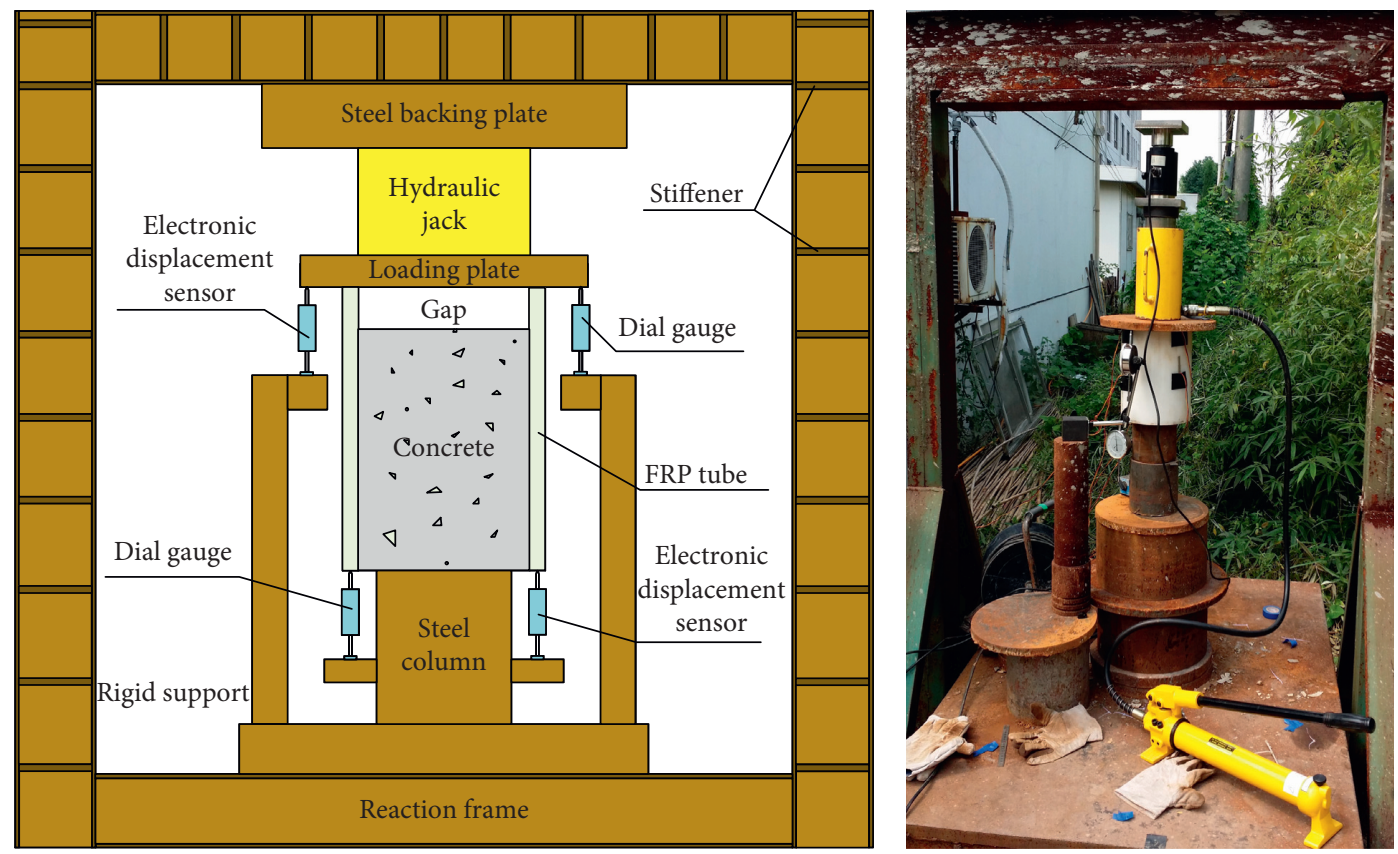

Figure 1: Test setup.

gauges' data were collected by the DH3816 static strain test system.

The slow speed load method was selected for all the tests, and each applied load was about one-tenth of estimated ultimate bearing capacity, which was obtained through preliminary tests on specimens with different bond types. Loading stopped when the slip remained stable or the concrete came into contact with the loading plate.

Test results would be expressed by the following parameters:

$\tau$, average bond stress $(\mathrm{kPa})$, which is a general designation of the interfacial bond stress between FRP tube and concrete, the anchoring force between internal threads and concrete and the anchoring force between shear connectors and concrete. $\tau$ could be calculated as follows:

$$
\tau=\frac{F}{\pi d L_{e}}
$$

where $F$ is the load applied by the hydraulic jack on FRP tube; $d$ is inside diameter of FRP tube; and $L_{e}$ is bond length between concrete and FRP tube.

It should be noted that actual bond stress between FRP tube and concrete is not constant, and there is an effective bond length of the interface [28]. Because this article is mainly concerned with the overall performance of bond stress rather than local bond stress, equation (1). is used here.

$\tau_{u}$, the maximum $\tau(\mathrm{kPa})$, which should be used for the design of FRP-confined concrete piles with shear connectors.

$\tau_{r}$, ultimate average bond stress $(\mathrm{kPa})$, which is the constant value of bond stress at the end of $\tau-s$ curves and should be used for the design of direct bond FRPconfined concrete piles and FRP-confined concrete piles with internal threads. $s$, average slip between FRP tube and concrete ( $\mathrm{mm})$, which is the average displacement of top surface and bottom surface of the FRP tube measured by electronic displacement sensors, based on the assumption that the deformation of concrete and FRP tube is ignorable.

$s_{u}$, average slip between FRP tube and concrete when $\tau$ reached $\tau_{u}(\mathrm{~mm})$.

$s_{r}$, average slip between FRP tube and concrete when $\tau$ reached $\tau_{r}(\mathrm{~mm})$.

\section{Results and Discussion}

Test results of 29 specimens are used to evaluate the bond behavior between FRP tube and concrete. Some important factors that influence bond behavior are examined in the following section.

3.1. Influence of the Bond Type on Bond Behavior. As mentioned earlier, all specimens were divided into three types according to bond type: direct bond specimens, specimens with internal threads, and specimens with shear connectors. Because direct bond specimens with normal concrete had low bond stress and limited test data were obtained, P-1, P-2 and P-3 with expansive concrete were selected to represent these three types of specimens to study the influence of bond type on bond behavior. All parameters of P-1, P-2, and P-3 were identical except the bond type, as shown in Table 1 . The test results of $\mathrm{P}-1, \mathrm{P}-2$, and $\mathrm{P}-3$ are shown in Table 4 and Figure 5 .

Obviously, bond type is a considerable factor affecting bond stress between FRP tube and concrete, and different bond types result in different $\tau-s$ curves and failure modes. For P-1, $\tau$ increases with increasing $s$ and remains stable after a small decrease and the specimen fails by shear failure 
TABle 1: Parameters of specimens.

\begin{tabular}{|c|c|c|c|c|c|c|c|c|}
\hline Code & Bond type & $\begin{array}{c}\text { Outside diameter } \\
\text { of FRP tube } D \\
(\mathrm{~mm})\end{array}$ & $\begin{array}{c}\text { Thickness of } \\
\text { FRP tube } t \\
(\mathrm{~mm})\end{array}$ & $\begin{array}{c}\text { Length of } \\
\text { FRP tube } L \\
(\mathrm{~mm})\end{array}$ & $\begin{array}{l}\text { Slenderness ratio } \\
\text { of FRP tube }(L / D)\end{array}$ & $\begin{array}{l}\text { Radius-thickness } \\
\text { ratio of FRP tube } \\
(D / t)\end{array}$ & $\begin{array}{l}\text { Concrete } \\
\text { type }\end{array}$ & $\begin{array}{l}\text { Concrete } \\
\text { stress }\end{array}$ \\
\hline $1-1$ & Direct bond & 200 & 11 & 100 & 0.5 & 18.2 & Normal & C30 \\
\hline $1-2$ & $\begin{array}{l}\text { Internal } \\
\text { threads }\end{array}$ & 200 & 11 & 100 & 0.5 & 18.2 & Normal & C30 \\
\hline $1-3$ & $\begin{array}{c}\text { Shear } \\
\text { connectors }\end{array}$ & 200 & 11 & 100 & 0.5 & 18.2 & Normal & C30 \\
\hline $2-1$ & Direct bond & 200 & 11 & 200 & 1 & 18.2 & Normal & $\mathrm{C} 30$ \\
\hline $2-2$ & $\begin{array}{l}\text { Internal } \\
\text { threads }\end{array}$ & 200 & 11 & 200 & 1 & 18.2 & Normal & $\mathrm{C} 30$ \\
\hline $2-3$ & $\begin{array}{c}\text { Shear } \\
\text { connectors }\end{array}$ & 200 & 11 & 200 & 1 & 18.2 & Normal & $\mathrm{C} 30$ \\
\hline $3-1$ & Direct bond & 200 & 11 & 400 & 2 & 18.2 & Normal & $\mathrm{C} 30$ \\
\hline $3-2$ & $\begin{array}{l}\text { Internal } \\
\text { threads }\end{array}$ & 200 & 11 & 400 & 2 & 18.2 & Normal & C30 \\
\hline $3-3$ & $\begin{array}{c}\text { Shear } \\
\text { connectors }\end{array}$ & 200 & 11 & 400 & 2 & 18.2 & Normal & $\mathrm{C} 30$ \\
\hline $4-1$ & Direct bond & 400 & 13 & 800 & 2 & 30.8 & Normal & $\mathrm{C} 30$ \\
\hline $4-2$ & $\begin{array}{l}\text { Internal } \\
\text { threads }\end{array}$ & 400 & 13 & 800 & 2 & 30.8 & Normal & C30 \\
\hline $4-3$ & $\begin{array}{c}\text { Shear } \\
\text { connectors }\end{array}$ & 400 & 13 & 800 & 2 & 30.8 & Normal & C30 \\
\hline $5-1$ & Direct bond & 400 & 13 & 400 & 1 & 30.8 & Normal & $\mathrm{C} 30$ \\
\hline $5-2$ & $\begin{array}{l}\text { Internal } \\
\text { threads }\end{array}$ & 400 & 13 & 400 & 1 & 30.8 & Normal & C30 \\
\hline $5-3$ & $\begin{array}{c}\text { Shear } \\
\text { connectors }\end{array}$ & 400 & 13 & 400 & 1 & 30.8 & Normal & $\mathrm{C} 30$ \\
\hline $6-1$ & Direct bond & 400 & 13 & 200 & 0.5 & 30.8 & Normal & $\mathrm{C} 30$ \\
\hline $6-2$ & $\begin{array}{l}\text { Internal } \\
\text { threads }\end{array}$ & 400 & 13 & 200 & 0.5 & 30.8 & Normal & C30 \\
\hline $6-3$ & $\begin{array}{c}\text { Shear } \\
\text { connectors }\end{array}$ & 400 & 13 & 200 & 0.5 & 30.8 & Normal & $\mathrm{C} 30$ \\
\hline $7-1$ & Direct bond & 200 & 15 & 200 & 1 & 13.3 & Normal & C30 \\
\hline $7-2$ & $\begin{array}{l}\text { Internal } \\
\text { threads }\end{array}$ & 200 & 15 & 200 & 1 & 13.3 & Normal & C30 \\
\hline $7-3$ & $\begin{array}{c}\text { Shear } \\
\text { connectors }\end{array}$ & 200 & 15 & 200 & 1 & 13.3 & Normal & $\mathrm{C} 30$ \\
\hline $8-1$ & Direct bond & 400 & 17 & 400 & 1 & 23.5 & Normal & $\mathrm{C} 30$ \\
\hline $8-2$ & $\begin{array}{l}\text { Internal } \\
\text { threads }\end{array}$ & 400 & 17 & 400 & 1 & 23.5 & Normal & C30 \\
\hline $8-3$ & $\begin{array}{c}\text { Shear } \\
\text { connectors }\end{array}$ & 400 & 17 & 400 & 1 & 23.5 & Normal & $\mathrm{C} 30$ \\
\hline $9-1$ & Direct bond & 200 & 11 & 200 & 1 & 18.2 & Normal & $\mathrm{C} 50$ \\
\hline $10-1$ & Direct bond & 200 & 11 & 200 & 1 & 18.2 & Normal & C60 \\
\hline P-1 & Direct bond & 200 & 11 & 400 & 2 & 18.2 & Expansive & C30 \\
\hline P-2 & $\begin{array}{l}\text { Internal } \\
\text { threads }\end{array}$ & 200 & 11 & 400 & 2 & 18.2 & Expansive & C30 \\
\hline P-3 & $\begin{array}{c}\text { Shear } \\
\text { connectors }\end{array}$ & 200 & 11 & 400 & 2 & 18.2 & Expansive & C30 \\
\hline
\end{tabular}

TABle 2: Properties of GFRP.

\begin{tabular}{lccccccc}
\hline Material & $\begin{array}{c}\text { Specific } \\
\text { gravity }\end{array}$ & $\begin{array}{c}\text { Tensile stress } \\
(\mathrm{GPa})\end{array}$ & $\begin{array}{c}\text { Elastic modulus } \\
(\mathrm{GPa})\end{array}$ & $\begin{array}{c}\text { Thermal expansion } \\
\text { coefficient }\left(10^{-6} /{ }^{\circ} \mathrm{C}\right)\end{array}$ & $\begin{array}{c}\text { Elongation } \\
(\%)\end{array}$ & $\begin{array}{c}\text { Specific stress } \\
(\mathrm{GPa})\end{array}$ & $\begin{array}{c}\text { Specific modulus } \\
(\mathrm{GPa})\end{array}$ \\
\hline GFRP & 2.65 & 3.4 & 52 & 5.1 & 4.7 & 1.41 & 32 \\
\hline
\end{tabular}

of FRP tube-concrete interface, as shown in Figure 6(a). For $\mathrm{P}-2$, the global behavior of $\tau-s$ curve is characterised by an initial increase in $\tau$ with little $s$, followed by softening once $\tau_{u}$ is attained and keeping stable after softening. This specimen fails by the deformation of internal threads. For P-3, $\tau$ shows a law of continuous growth and shear connectors are pulled 


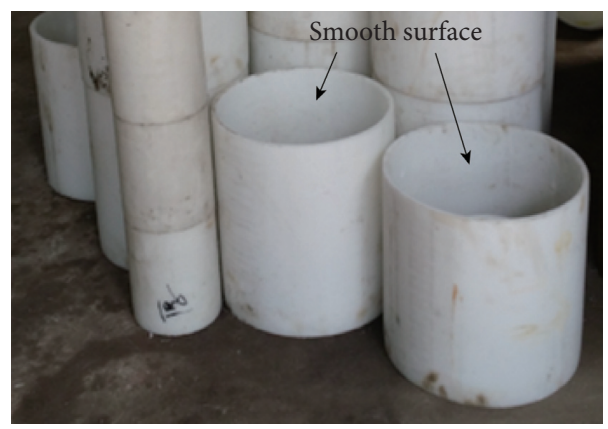

(a)

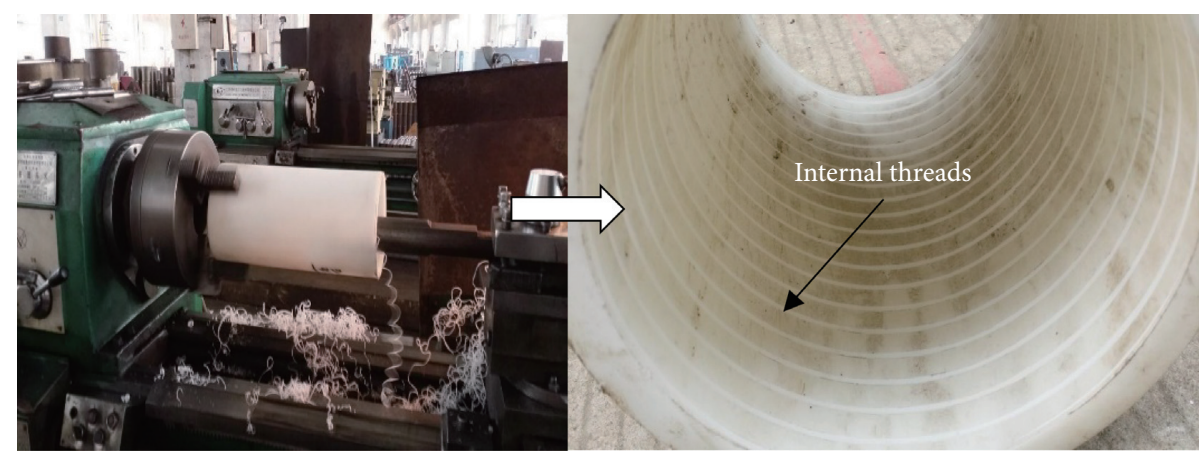

(b)

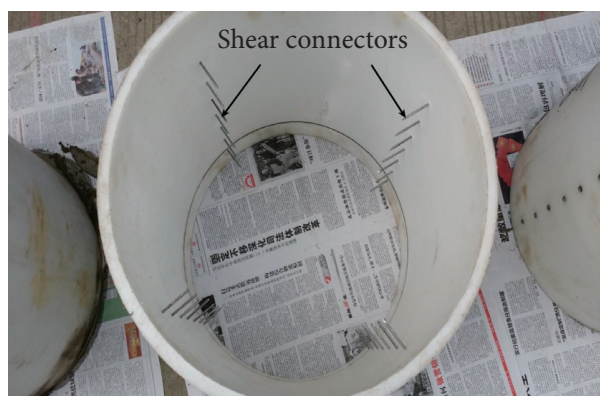

(c)

Figure 2: Different types of FRP tubes. (a) Normal FRP tubes. (b) FRP tube with internal threads. (c) FRP tube with shear connectors.

out (Figure 6(b)). The maximum $\tau_{u}$ appears in $\mathrm{P}-2$, which is $418.45 \mathrm{kPa}, \tau_{u}$ of $\mathrm{P}-3$ is slightly lower than that of $\mathrm{P}-2$, and $\mathrm{P}-1$ exhibits the lowest $\tau_{u}$, which is only $12 \%$ of P-2. However, it should be noted that $s_{u}$ of both P-1 and P-2 are less than $4 \mathrm{~mm}$, while $s_{u}$ of P-3 is more than $35 \mathrm{~mm}$. The reason for the above differences can be attributed to the different bearing mechanisms: direct bond specimens rely on interfacial friction and chemical adhesion between FRP tube and concrete to resist shear stress, whereas specimens with internal threads and specimens with shear connectors have anchoring force between internal threads and concrete and anchoring force between shear connectors and concrete, respectively, in addition to interfacial friction and chemical adhesion. For specimens with shear connectors, shear connectors still could provide anchoring force even if they are pulled into the FRP tube by concrete, leading to a relatively large $s_{u}$; however, anchorage force between internal threads and concrete and chemical adhesion would decrease dramatically after $\tau$ reaching $\tau_{u}$, which is the reason for the softening stage of direct bond specimens and specimens with internal threads.
3.2. Influence of the Slenderness Ratio on Bond Behavior. As mentioned above, direct bond specimens with normal concrete have low bond stress, and limited test data were collected, so the following analysis of influencing factors mainly focuses on specimens with internal threads and specimens with shear connectors.

3.2.1. Specimens with Internal Threads. Test results of two groups of specimens (each group has three specimens) are used to demonstrate how slenderness ratio of the FRP tube influences on bond behavior of specimens with internal threads. The slenderness ratios vary from 0.5 to 2 in both groups, and the radius-thickness ratios are 18.2 in Group A-1 and 30.8 in Group A-2 separately. Test results of Group A-1 and A-2 are provided in Table 5 and Figure 7.

As seen from Figure 7, although the values of $\tau_{u}$ are significantly different, the development law of $\tau-s$ curves of six specimens is consistent, which could prove the correctness of the test results. For the three specimens in 


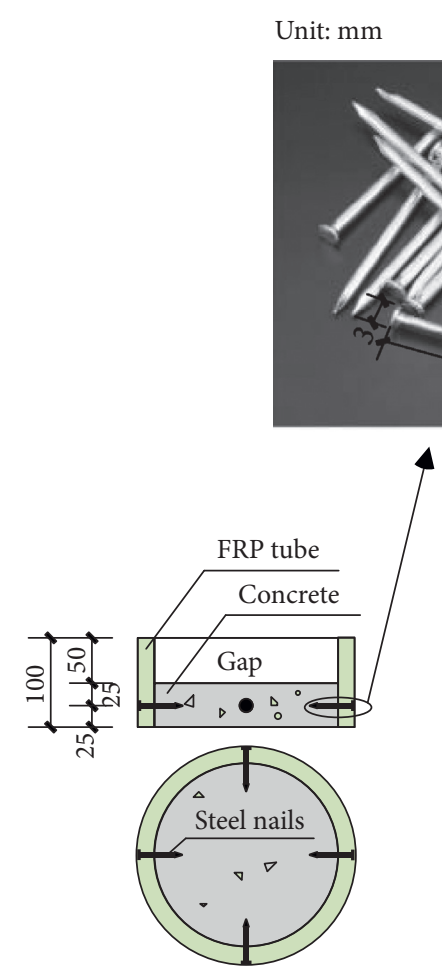

(a)

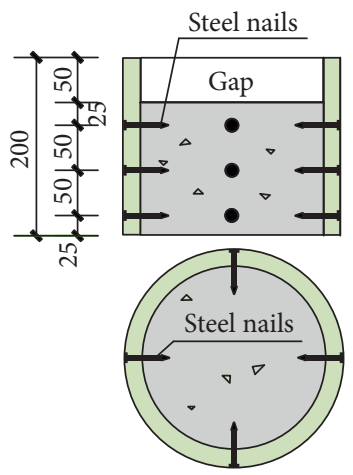

(b)

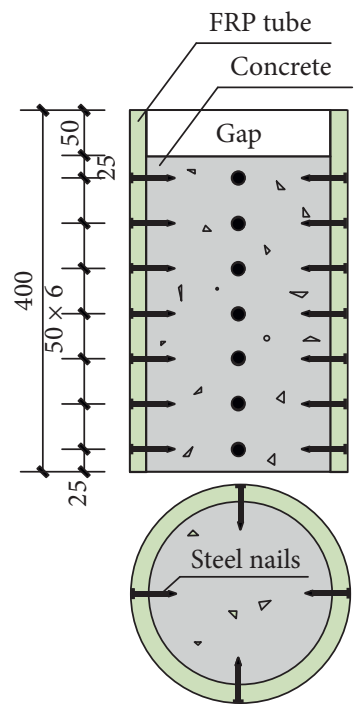

(c)

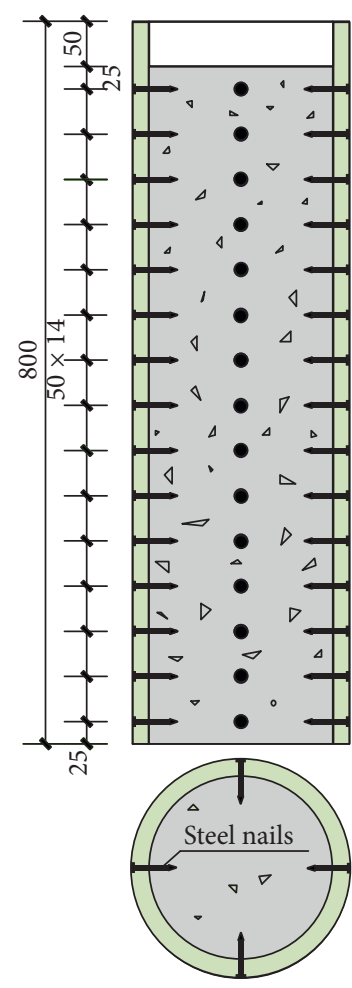

(d)

Figure 3: Number and positions of shear connectors of specimens with different lengths. (a) $100 \mathrm{~mm}$. (b) $200 \mathrm{~mm}$. (c) $400 \mathrm{~mm}$. (d) $800 \mathrm{~mm}$.

TABle 3: Properties of concrete.

\begin{tabular}{lcccc}
\hline Concrete stress & $\begin{array}{c}\text { Mix proportion (cement: water: sand: } \\
\text { stone) }\end{array}$ & Sand ratio (\%) & $\begin{array}{c}\text { Water-cement } \\
\text { ratio }\end{array}$ & Mean cubic compressive stress (MPa) \\
\hline C30 & $450: 183: 600: 1192$ & 33.5 & 0.41 & $31.2(\mathrm{CV}=3.76 \%)$ \\
C50 & $510: 178: 545: 1220$ & 30.9 & 0.35 & $52.1(\mathrm{CV}=1.65 \%)$ \\
C60 & $525: 180: 530: 1250$ & 29.8 & 0.34 & $59.1(\mathrm{CV}=3.44 \%)$ \\
\hline
\end{tabular}

Group A-1, $\tau_{u}$ of 1-2 and 2-2 are nearly the same, which are $509.65 \mathrm{kPa}$ and $491.77 \mathrm{kPa}$, respectively, while $\tau_{u}$ of 3-2 is $335.30 \mathrm{kPa}$, only $65.8 \%$ of $1-2$. In terms of $\tau_{r}$, the maximum value occurs in 2-2, followed by 1-2 and 3-2. Obviously, in Group A-1, there is no linear relation among $\tau_{u}, \tau_{r}$, and slenderness ratio of the FRP tube. However, for 6-2 in Group A-2, whose slenderness ratio is $0.5, \tau_{u}$, and $\tau_{r}$ are $102.13 \mathrm{kPa}$ and $28 \mathrm{kPa}$, respectively. For $5-2$, whose slenderness ratio is $1, \tau_{u}$ and $\tau_{r}$ are $144.3 \mathrm{kPa}$ and $63.83 \mathrm{kPa}$, and for $4-2$, whose slenderness ratio is $2, \tau_{u}$ and $\tau_{r}$ are $187.14 \mathrm{kPa}$ and $93.09 \mathrm{kPa}$. It is obvious that $\tau_{r}$ increases with the increase of $\tau_{u}$, and a linear relationship could be found between bond stress $\left(\tau_{u}\right.$ or $\left.\tau_{r}\right)$ and slenderness ratio in Group A-2. As to $s_{u}$, the smallest one in two groups appears in the specimens with slenderness ratio of 0.5 , but the largest one appeared in the specimens with slenderness ratio of 1 , implying that $s_{u}$ does not have direct relation with the slenderness ratio.

Different groups obtain different relationships between bond stress and slenderness ratio. In order to gain a deep understanding of this relationship, test results of specimens with shear connectors are shown below.
3.2.2. Specimens with Shear Connectors. Test results of two other groups of specimens (each group has three specimens) are analysed to show the effect of slenderness ratio of FRP tube on bond behavior of specimens with shear connectors. The parameters of Groups A-3 and A-4 are identical to those of Groups A-1 and A-2 except bond type. Test results of Groups A-3 and A-4 are provided in Table 6 and Figure 8 .

Similar to the test results of Group A-1 and A-2, $\tau-s$ curves of these six specimens in Group A-3 and A-4 also show a same development law. However, some common points could be found in test results of Group A-3 and A-4: firstly, both the maximum $\tau_{u}$ and the maximum $\tau_{r}$ appeared in specimens with slenderness ratio of 1 , and both the minimum $\tau_{u}$ and the minimum $\tau_{r}$ appeared in specimens, whose slenderness ratio is 0.5 ; secondly, bond stress $\left(\tau_{u}\right.$ or $\tau_{r}$ ) does not increase or decrease with the increase of the slenderness ratio, and the relationship between bond stress and slenderness ratio is uncertain; thirdly, the minimum $s_{u}$ appears in specimens with slenderness ratio of 0.5 , while the maximum one appears in specimens with slenderness ratio of 1 . 


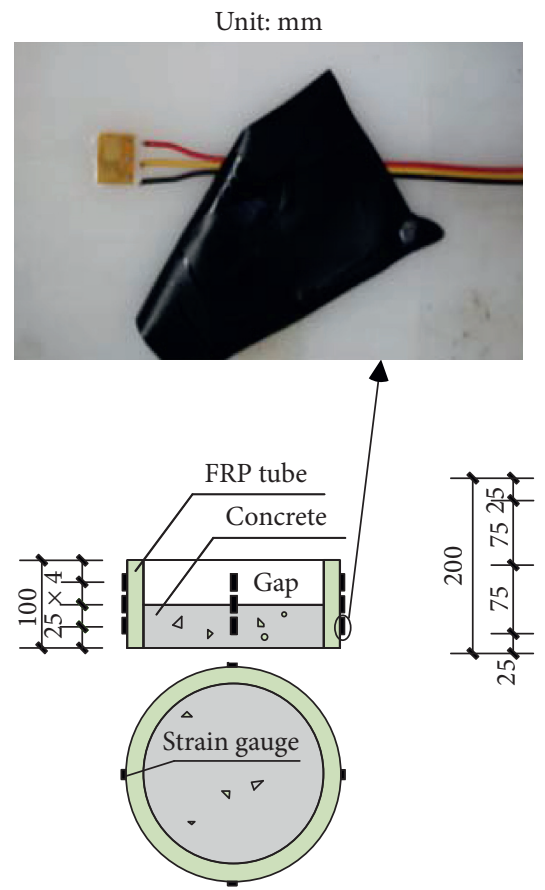

(a)
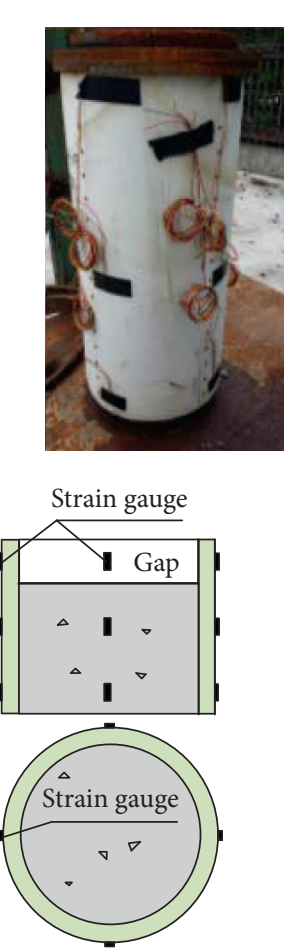

(b)

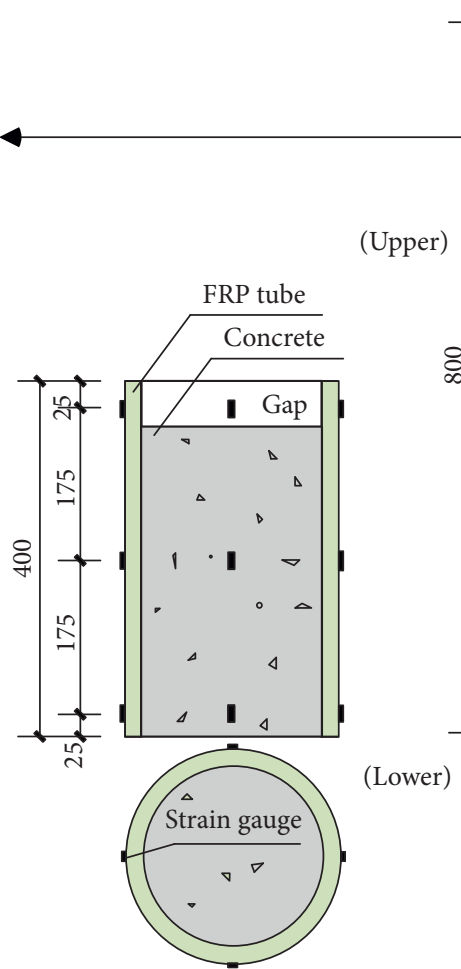

(c)

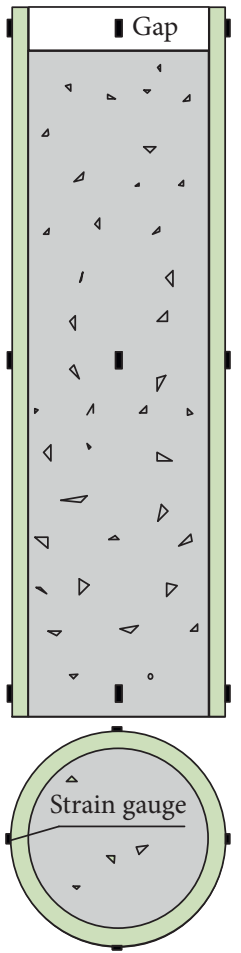

(d)

FIgURE 4: Number and position of strain gauges of specimens with different lengths. (a) $100 \mathrm{~mm}$. (b) $200 \mathrm{~mm}$. (c) $400 \mathrm{~mm}$. (d) $800 \mathrm{~mm}$.

TABle 4: Test results of specimens P-1, P-2, and P-3.

\begin{tabular}{lcccc}
\hline Code & Bond type & $\tau_{u}(\mathrm{kPa})$ & $s_{u}(\mathrm{~mm})$ & $\tau_{r}(\mathrm{kPa})$ \\
\hline $\mathrm{P}-1$ & Direct bond & 59.46 & 3.56 & 57.22 \\
$\mathrm{P}-2$ & Internal threads & 418.45 & 1.87 & 307.58 \\
$\mathrm{P}-3$ & Shear connectors & 382.24 & 37.51 & 385.37 \\
\hline
\end{tabular}

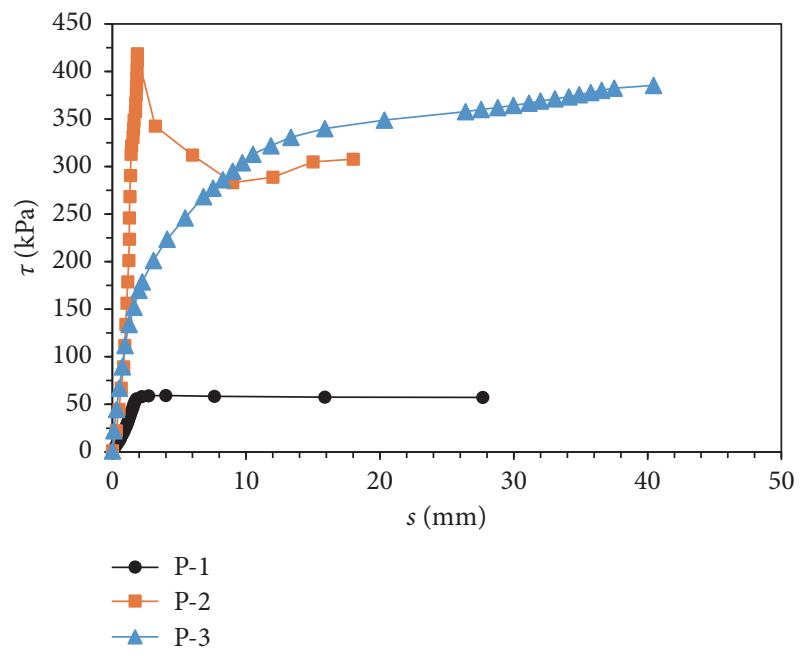

FIGURE 5: $\tau-s$ curves of specimens P-1, P-2, and P-3.

Based on test results of specimens with internal threads and specimens with shear connectors, the following conclusion can be drawn: there is no obvious correlation between slenderness ratio and bond stress (and $s_{u}$ ). This phenomenon can be explained by the following reasons: the resulting bond stress and $s_{u}$ is a combined effect of various factors, not limited to those mentioned in this paper; slenderness ratio, as one of the many influencing factors, is the one with less influence; under the influence of other factors, $\tau-s$ curve is less sensitive to the change of slenderness ratio and exhibits irregularity.

\subsection{Influence of the Radius-Thickness Ratio on Bond Behavior}

3.3.1. Specimens with Internal Threads. Test results of Groups B1 (7-2 and 2-2) and B2 (8-2 and 4-2) are used to study the influence of the radius-thickness ratio of FRP tubes on bond behavior of specimens with internal threads. Four specimens have the same slenderness ratio, concrete type and concrete stress, except radius-thickness ratio, which varies from 13.3 to 30.8 , as shown in Table 1 . Test results are listed in Table 7 , and $\tau-s$ curves of these four specimens are plotted in Figure 9.

Figure 9 clearly illustrates that in Group B-1, $\tau_{u}$ of specimen 7-2, whose radius-thickness ratio is 13.3 , is $636.62 \mathrm{kPa}$, while $\tau_{u}$ of specimen $2-2$, whose radius-thickness ratio is 18.2 , is only $491.80 \mathrm{kPa}$, accounting for $77.25 \%$ of 7-2. The same phenomenon can also be found in Group B-2: compared with specimen 4-2, radius-thickness ratio of 8-2 is relatively small. But $\tau_{u}$ when the outer diameter changes, dryshrinkage during curing changes and lateral expansion under applied load of concrete is different. The reason why $\tau_{u}$ increases as radius-thickness decreases is, for specimens with internal threads, shear stress is completely offset by the interaction between concrete and the FRP tube. 


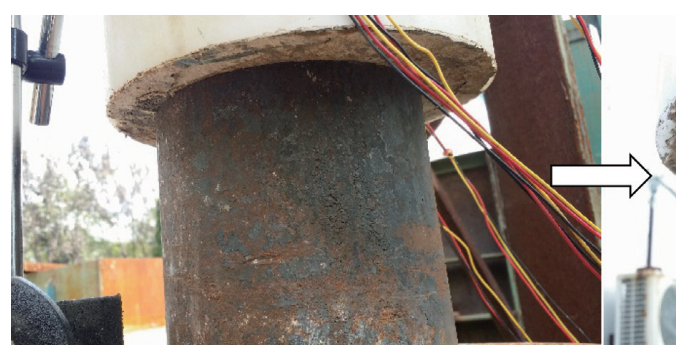

(a)

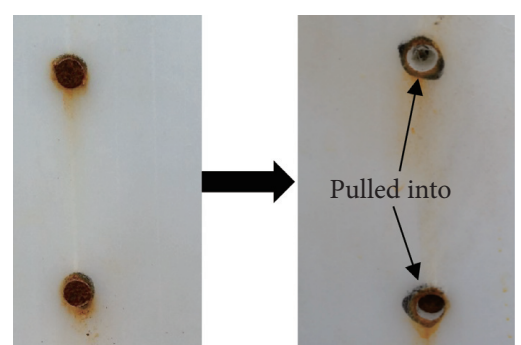

(b)

FIGURE 6: Failure modes of specimens. (a) Shear failure of FRP tube-concrete interface. (b) Shear connectors were pulled out.

TABLE 5: Test results of specimens in Group A-1 and A-2.

\begin{tabular}{|c|c|c|c|c|c|c|c|}
\hline Group & Code & Bond type & $\begin{array}{l}\text { Radius-thickness ratio of FRP tube } \\
\qquad(D / t)\end{array}$ & $\begin{array}{l}\text { Slenderness ratio of FRP tube } \\
(L / D)\end{array}$ & $\tau_{u}(\mathrm{kPa})$ & $s_{u}(\mathrm{~mm})$ & $\tau_{r}(\mathrm{kPa})$ \\
\hline \multirow{3}{*}{ A-1 } & $1-2$ & Internal threads & 18.2 & 0.5 & 509.65 & 2.09 & 245.35 \\
\hline & $2-2$ & Internal threads & 18.2 & 1 & 491.77 & 4.04 & 324.12 \\
\hline & $3-2$ & Internal threads & 18.2 & 2 & 335.30 & 3.62 & 146.84 \\
\hline \multirow{3}{*}{ A-2 } & $6-2$ & Internal threads & 30.8 & 0.5 & 102.13 & 1.02 & 28.00 \\
\hline & $5-2$ & Internal threads & 30.8 & 1 & 144.89 & 4.80 & 63.83 \\
\hline & $4-2$ & Internal threads & 30.8 & 2 & 187.14 & 3.46 & 93.09 \\
\hline
\end{tabular}

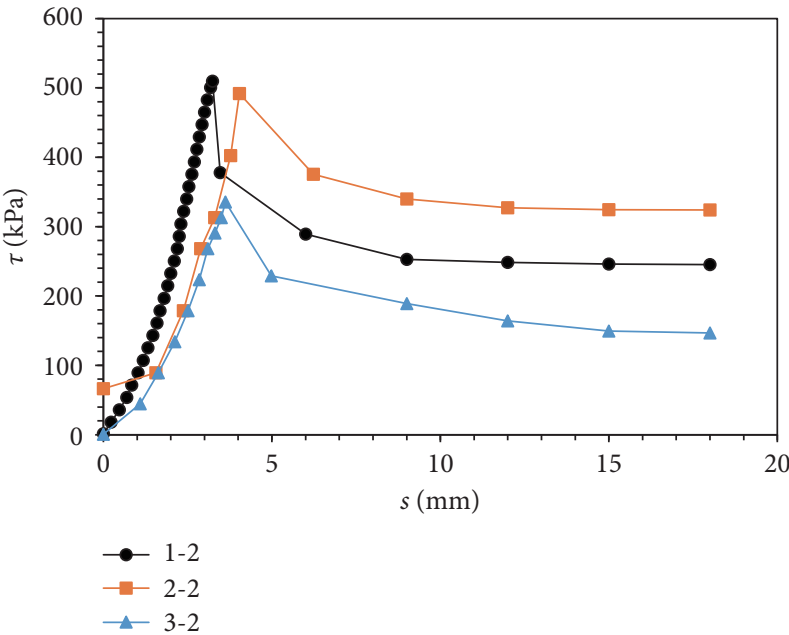

(a)

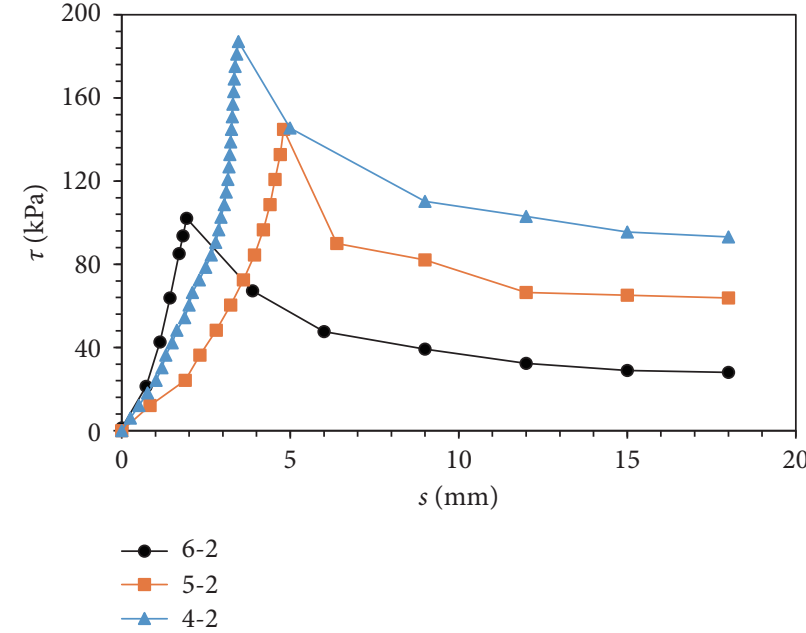

(b)

Figure 7: $\tau-s$ curves of Group A-1 and A-2. (a) $\tau-s$ curves of Group A-1. (b) $\tau-s$ curves of Group A-2.

As the applied load increases, lateral expansion of concrete increases significantly, and the FRP tube starts to restrict the lateral deformation of the concrete. When outer diameters of specimens are the same, a larger thickness (a smaller radiusthickness ratio) means a smaller lateral deformation of the FRP tube, which can lead to a more powerful restriction of FRP tube on concrete [29]. So the bond stress of 7-2 and 8-2 is higher than 2-2 and 4-2, respectively. But when the outer diameter changes, dry shrinkage during curing changes and lateral expansion under applied load of concrete is different; although thickness of the FRP tube increases, its restriction effect may not be fully exerted, leading the bond stress of Group B-2 is smaller than Group B-1.

3.3.2. Specimens with Shear Connectors. Test results of B3 (7-3 and 2-3) and B4 (8-3 and 4-3) are chosen to investigate the effect of the radius-thickness ratio of the FRP tube on the bond behavior of specimens with shear connectors, as 
TABLE 6: Test results of specimens of Groups A-3 and A-4.

\begin{tabular}{|c|c|c|c|c|c|c|c|}
\hline Group & Code & Bond type & $\begin{array}{l}\text { Radius-thickness ratio of FRP tube } \\
(D / t)\end{array}$ & $\begin{array}{l}\text { Slenderness ratio of FRP tube } \\
(L / D)\end{array}$ & $\tau_{u}(\mathrm{kPa})$ & $s_{u}(\mathrm{~mm})$ & $\tau_{r}(\mathrm{kPa})$ \\
\hline \multirow{3}{*}{ A-3 } & $1-3$ & Shear connectors & 18.2 & 0.5 & 175.25 & 12.78 & 143.06 \\
\hline & $2-3$ & Shear connectors & 18.2 & 1 & 259.30 & 12.36 & 257.51 \\
\hline & $3-3$ & Shear connectors & 18.2 & 2 & 178.83 & 15.74 & 185.53 \\
\hline \multirow{3}{*}{ A-4 } & $6-3$ & Shear connectors & 30.8 & 0.5 & 93.62 & 8.65 & 102.98 \\
\hline & $5-3$ & Shear connectors & 30.8 & 1 & 144.89 & 14.26 & 164.81 \\
\hline & $4-3$ & Shear connectors & 30.8 & 2 & 126.78 & 11.99 & 135.83 \\
\hline
\end{tabular}

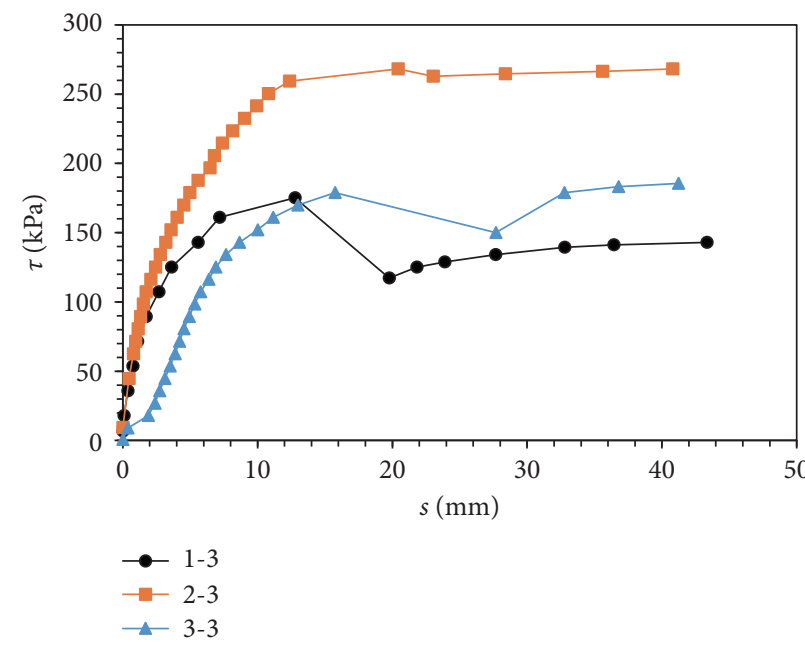

(a)

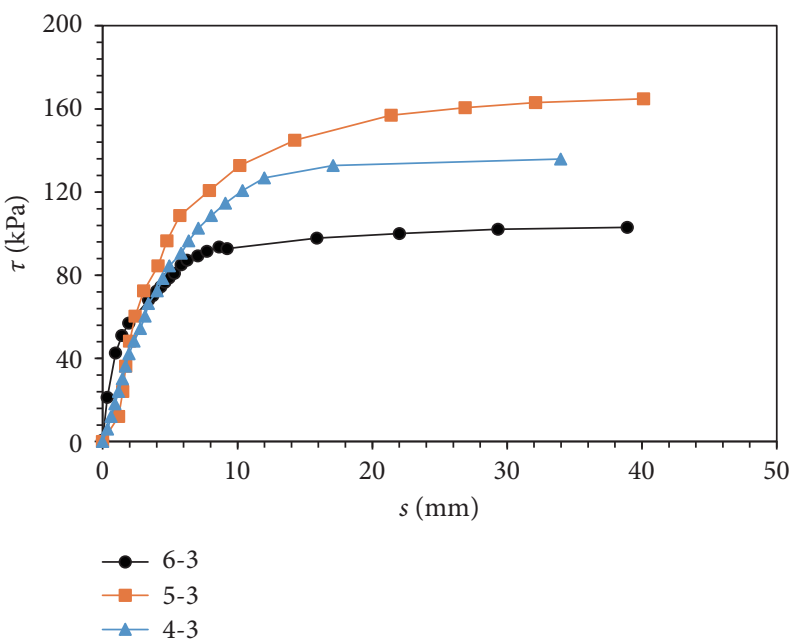

(b)

Figure 8: $\tau-s$ curves of Group A-3 and A-4. (a) $\tau-s$ curves of Group A-3. (b) $\tau-s$ curves of Group A-4.

TABle 7: Test results of specimens of Groups B-1 and B-2.

\begin{tabular}{cccccccc}
\hline Group & Code & Bond type & Geometry size $(D \times L \times t(\mathrm{~mm}))$ & Radius- thickness ratio $(D / t)$ & $\tau_{u}(\mathrm{kPa})$ & $S_{u}(\mathrm{~mm})$ & $\tau_{r}(\mathrm{kPa})$ \\
\hline \multirow{2}{*}{ B1 } & $7-2$ & Internal threads & $200 \times 200 \times 15$ & 13.3 & 636.62 & 3.33 & 295.84 \\
& $2-2$ & Internal threads & $200 \times 200 \times 11$ & 18.2 & 491.80 & 4.04 & 324.12 \\
\hline \multirow{2}{*}{ B2 } & $8-2$ & Internal threads & $400 \times 400 \times 17$ & 23.5 & 197.40 & 5.26 & 97.62 \\
& $4-2$ & Internal threads & $400 \times 400 \times 13$ & 30.8 & 144.89 & 4.80 & 63.83 \\
\hline
\end{tabular}

summarized in Table 8. $\tau-s$ curves of these four specimens are shown in Figure 10.

It can be seen from Figure 10 that $\tau_{u}$ of specimens with shear connectors does not increase as radius-thickness ratio decreases, which is completely different from the test results of specimens with internal threads: for Group B-4, radiusthickness ratio decreased by $23.7 \%$ (from 30.8 to 23.5), while $\tau_{u}$ increased only by $2.04 \%$ (from $144.89 \mathrm{kPa}$ to $147.85 \mathrm{kPa}$ ); for Group B-3, $\tau_{u}$ does not increase but decreases by $2.5 \%$ (from $259.30 \mathrm{kPa}$ to $252.78 \mathrm{kPa}$ ) when radius-thickness ratio decreases from 18.2 to 13.3. Different shear transfer methods between specimens with internal threads and specimens with shear connectors is the main reason for different influence of radius-thickness ratio on $\tau_{u}$. Specimens with shear connectors relies mainly on anchoring force between shear connectors and concrete to resist the shear stress, and the interaction between concrete and FRP tube contributes only a small part of the shear resistance. The change of radius-thickness ratio has little effect on anchoring force between shear connectors and concrete; therefore, macroscopically, $\tau_{u}$ is not directly related to radius-thickness ratio.

3.4. Influence of the Concrete Strength on Bond Behavior. In order to demonstrate the influence of concrete strength on bond behavior, specimens 2-1, 9-1 and 10-1 are picked out. The only variable of these three specimens is concrete 


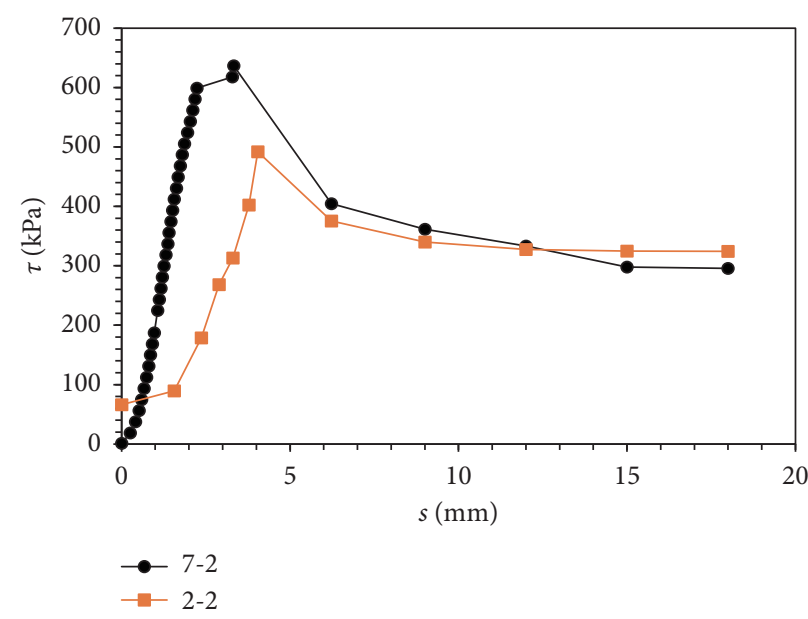

(a)

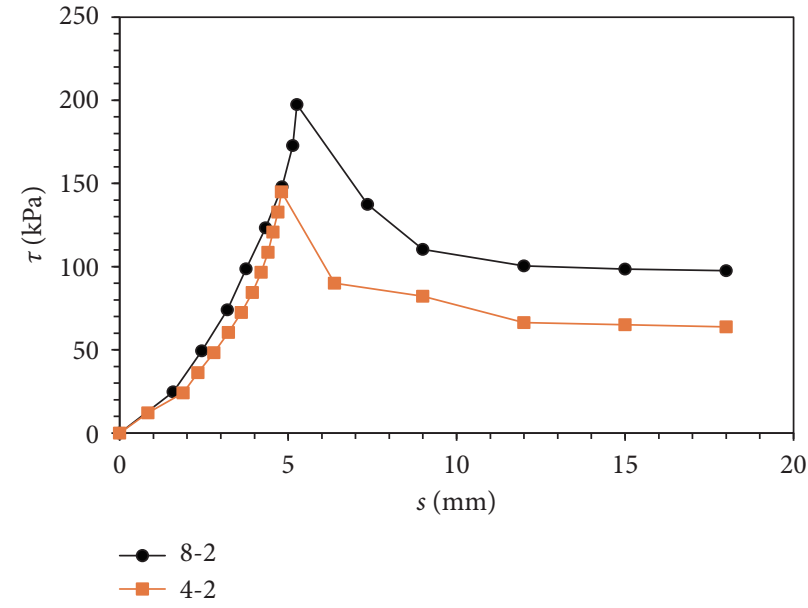

(b)

Figure 9: $\tau-s$ curves of Group B-1 and B-2. (a) $\tau-s$ curves of Group B-1. (b) $\tau-s$ curves of Group B-2.

Table 8: Test results of specimens of Groups B-3 and B-4.

\begin{tabular}{|c|c|c|c|c|c|c|c|}
\hline Group & Code & Bond type & Geometry size $(D \times L \times t(\mathrm{~mm}))$ & Radius-thickness ratio $(D / t)$ & $\tau_{u}(\mathrm{kPa})$ & $s_{u}(\mathrm{~mm})$ & $\tau_{r}(\mathrm{kPa})$ \\
\hline \multirow{2}{*}{ B3 } & $7-3$ & Shear connectors & $200 \times 200 \times 15$ & 13.3 & 252.78 & 14.19 & 249.03 \\
\hline & $2-3$ & Shear connectors & $200 \times 200 \times 11$ & 18.2 & 259.30 & 12.36 & 268.24 \\
\hline \multirow{2}{*}{ B4 } & $8-3$ & Shear connectors & $400 \times 400 \times 17$ & 23.5 & 147.85 & 12.71 & 171.33 \\
\hline & $5-3$ & Shear connectors & $400 \times 400 \times 13$ & 30.8 & 144.89 & 14.26 & 164.81 \\
\hline
\end{tabular}

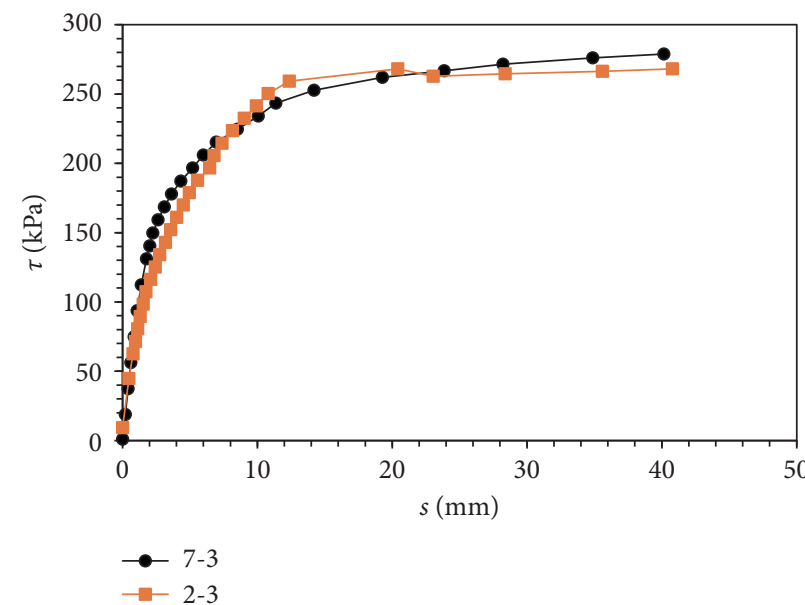

(a)

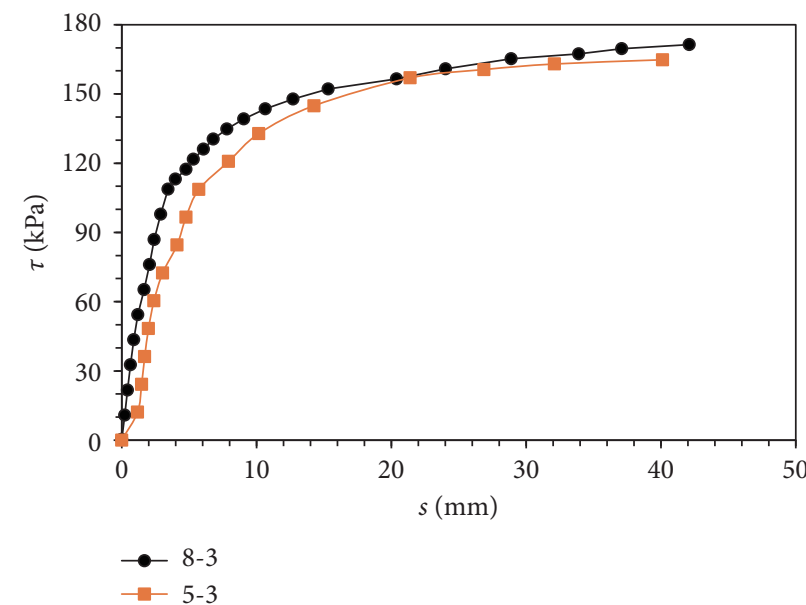

(b)

Figure 10: $\tau-s$ curves of Group B-3 and B-4. (a) $\tau-s$ curves of Group B-3. (b) $\tau-s$ curves of Group B-4.

TABLE 9: Test results of specimens 2-1, 9-1, and 10-1.

\begin{tabular}{lcccc}
\hline Code & Concrete strength & $\tau_{u}(\mathrm{kPa})$ & $s_{u}(\mathrm{~mm})$ & $\tau_{r}(\mathrm{kPa})$ \\
\hline $2-1$ & C30 & 5.36 & 1.43 & 1.07 \\
$9-1$ & C50 & 7.87 & 1.00 & 0.54 \\
$10-1$ & C60 & 10.73 & 0.40 & 0.89 \\
\hline
\end{tabular}

strength, which varies from C30 to C60. Test results are provided in Table 9 and Figure 11.

Although dry shrinkage of concrete and smooth inner surface of FRP tube resulted in very low bond stress of the direct bond specimens with normal concrete and limited data were collected during test process, a conclusion that a higher concrete strength is advantageous not only to obtain a higher $\tau_{u}$ but also to control $s_{u}$ could be got from Table 9 and Figure 11: for specimen 2-1, whose concrete strength is $\mathrm{C} 30, \tau_{u}$ is $5.36 \mathrm{kPa}$ and $s_{u}$ is $1.43 \mathrm{~mm}$. When concrete strength increases to C50 and C60, $\tau_{u}$ of 9-1 and 10-1 develops rapidly to $7.87 \mathrm{kPa}$ and $10.73 \mathrm{kPa}$ and $s_{u}$ is reduced to $1.00 \mathrm{~mm}$ and $0.40 \mathrm{~mm}$, respectively. This is because the higher the concrete strength is, the higher the interfacial cohesion between the FRP tube and concrete [30]. Although with the increase of the concrete stress, dry shrinkage increases, leading to a tendency for the concrete to debond from the 


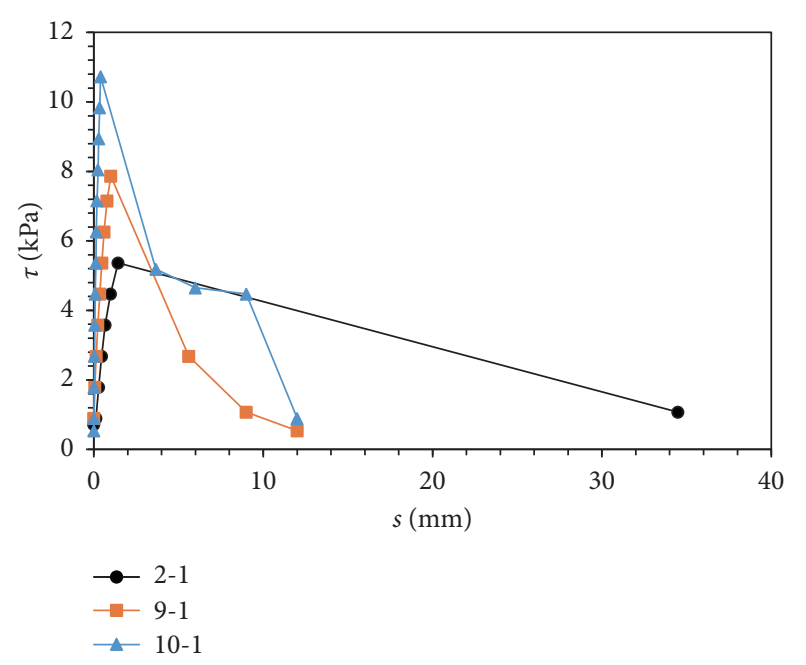

Figure 11: $\tau-s$ curves of specimens 2-1, 9-1, and 10-1.

FRP tube, bond stress still increases with the increase of concrete strength. These results are in accordance with the conclusions of Li et al. [17]. Because a higher interfacial cohesion of concrete is also beneficial to anchoring force between threads and concrete and anchoring force between shear connectors and concrete, it is reasonable to extend this conclusion, which is obtained by the tests on directly bond specimens, to the other two types of specimens.

\subsection{Influence of the Concrete Type on Bond Behavior.} Compared with normal concrete, expansive concrete is believed to have the ability to overcome concrete shrinkage and thus achieve in higher bond stress between concrete and FRP tube. In order to investigate this effect, three groups of specimens (Groups T-1, T-2, and T-3) are prepared, representing three types of bond type. Bond type, slenderness ratio, radius-thickness ratio, and concrete stress of each group are identical, except concrete type. Test results are listed in $\mathrm{Ta}-$ ble 10, and $\tau-s$ curves of every group are shown in Figure 12.

Figure 12 illustrates that $\tau_{u}$ and $\tau_{r}$ improve significantly after substituting expansive concrete for normal concrete in all three groups. In Group T-1, $\tau_{u}$ and $\tau_{r}$ of specimen 3-1 are only $6.26 \mathrm{kPa}$ and $1.16 \mathrm{kPa}$, while for specimen $\mathrm{P}-1, \tau_{u}$ and $\tau_{r}$ increase rapidly to $59.46 \mathrm{kPa}$ and $57.22 \mathrm{kPa}$, respectively. In Group T-2, which represents specimens with internal threads, specimen P-2 with expansive concrete enhances $\tau_{u}$ and $\tau_{r}$ by $125 \%$ and $210 \%$ and reduces $s_{u}$ by $48 \%$ than specimen $3-2$ with normal concrete. In group $\mathrm{T}-3, \tau_{u}$ reaches $382.24 \mathrm{kPa}$ for specimen P-3, while for specimen $3-3$, it is only $178.83 \mathrm{kPa} ; \tau_{r}$ of specimen 3-3 is also only half of specimen P-3. It is clear that although both the improvement of concrete strength and the use of expansive concrete can increase the interaction between concrete and FRP tube, compared with the improvement of concrete strength, the use of expansive concrete is more efficient, and both $\tau_{u}$ and $\tau_{r}$ have a greater increase.

3.6. Distribution and Development Law of Axial Strain. The axial strain distribution and development law along the height of FRP tube are evaluated by strain gauges at different locations. Because the bond type and concrete type have a great influence on distribution and development law of axial strain, analysis is based on test results of specimens with different bond types and concrete types. The strain analyzed below is the average value of four strain gauges of the same cross section (see Figure 4).

3.6.1. Specimens with Internal Threads. 4-2 and P-2 representing the specimens with normal concrete and expansive concrete are picked out to study the axial stains of specimens with internal threads. It can be seen from Figures 13 and 14 that distribution and development law of axial strain of normal concrete specimens, and expansive concrete specimens are completely different.

For specimen 4-2, development of strain at different heights is relatively balanced and consistent. All strain is maintained at a very small value when slip is less than $1 \mathrm{~mm}$, but when slip exceeds $3 \mathrm{~mm}$, strain increases markedly. Eventually, the upper strain is greater than the middle strain, which is larger than the lower strain, and an almost uniform strain distribution along the height of FRP tube is observed. The reason for this phenomenon may be that when the applied load is small, the load is resisted by elastic interlock between internal threads and concrete, and no deformation of FRP tube occurs. As the applied load increases, the internal threads distort gradually, leading to a small deformation of FRP tube. Finally, when the internal threads are completely broken, the strain of FRP tube suddenly increases.

However, for P-2, strain of FRP tube develops gradually from top to bottom. The upper strain increases linearly from beginning to end, the middle strain begins to grow linearly after the slip reaches $0.25 \mathrm{~mm}$, and the bottom strain begins to increase exponentially with a higher growth rate until the slip reaches $1 \mathrm{~mm}$. The final strain distribution along the height of FRP tube is a polygonal line.

The reason for the differences discussed above is considered to be the bond stress of expansive concrete specimens, which is larger than normal concrete specimens. For expansive concrete specimens, bond stress of upper part of specimen can offset the load completely under small load, and the load cannot be transferred to the lower part. As the load increases, the bond stress of the middle and lower parts gradually exerts. However, normal concrete specimens have a small bond stress, and the bond stress of the entire interface needs to be exerted under a small load. Therefore, the strains of the upper, middle, and lower parts are relatively close.

3.6.2. Specimens with Shear Connectors. Figures 15 and 16 show strain-slip curves and strain-height curves of specimens with shear connectors (4-3 and P-3 represent normal concrete specimens and expansive concrete specimens separately). By comparison, it can be found that there are many similarities between the two specimens: first, both strain-slip curves exhibit ductile behaviors: when slip is less than $7 \mathrm{~mm}$, the strain increases with the increase of slip, and the strain remains stable after the slip exceeds $7 \mathrm{~mm}$. Second, the upper strain is greater than the middle strain, which is greater than the lower strain. The second similarity is in line with the results of specimens 
TABLe 10: Test results of the specimens in Groups T-1, T-2, and T-3.

\begin{tabular}{|c|c|c|c|c|c|c|}
\hline Group & Code & Bond type & Concrete type & $\tau_{u}(\mathrm{kPa})$ & $s_{u}(\mathrm{~mm})$ & $\tau_{r}(\mathrm{kPa})$ \\
\hline \multirow{2}{*}{ T-1 } & $3-1$ & Direct bond & Normal & 6.26 & 2.90 & 1.16 \\
\hline & $\mathrm{P}-1$ & Direct bond & Expansive & 59.46 & 1.56 & 57.22 \\
\hline \multirow{2}{*}{ T-2 } & $3-2$ & Internal threads & Normal & 335.30 & 3.62 & 146.64 \\
\hline & $\mathrm{P}-2$ & Internal threads & Expansive & 418.45 & 1.87 & 307.58 \\
\hline \multirow{2}{*}{$\mathrm{T}-3$} & $3-3$ & Shear connectors & Normal & 178.83 & 41.22 & 185.53 \\
\hline & $\mathrm{P}-3$ & Shear connectors & Expansive & 382.24 & 37.51 & 385.37 \\
\hline
\end{tabular}

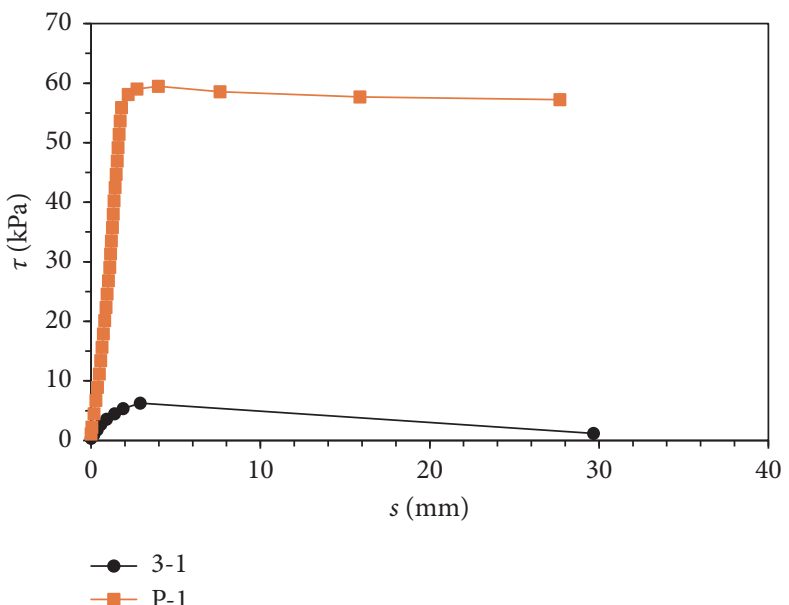

(a)

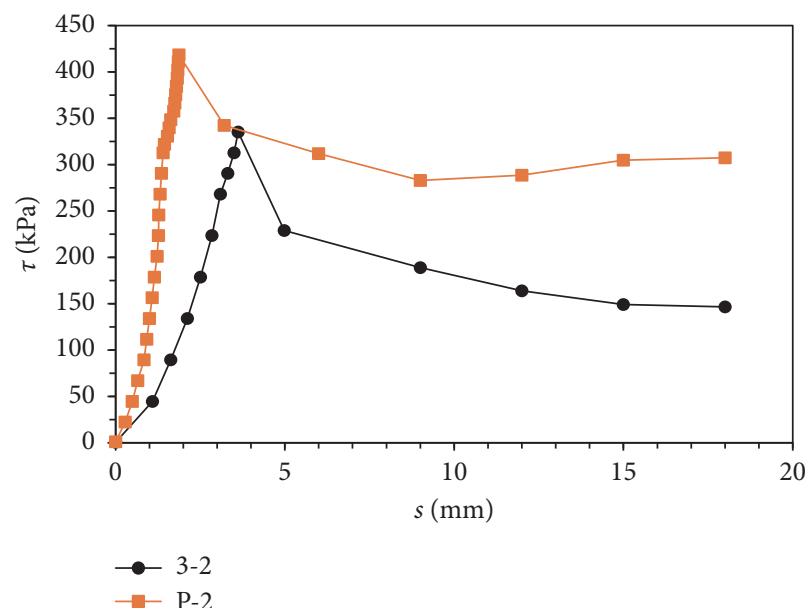

(b)

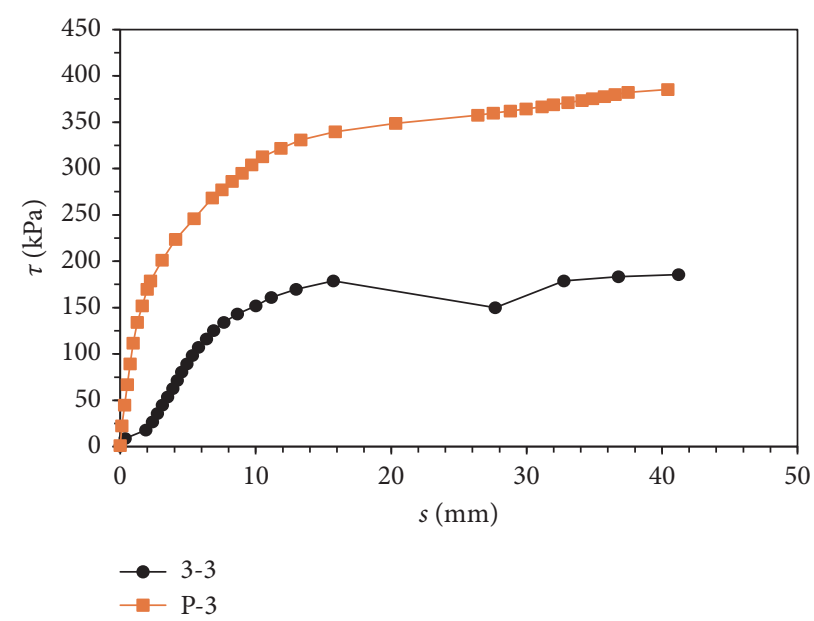

(c)

Figure 12: $\tau-s$ curves of specimens T-1, T-2, and T-3. (a) $\tau-s$ curves of Group T-1. (b) $\tau-s$ curves of Group T-2. (c) $\tau-s$ curves of Group T-3.

with internal threads, but the difference between the upper stain and the lower strain is significantly larger, illustrating that the load transfer process from top to bottom is slower for specimens with shear connectors. The same conclusion can be drawn from the change of the slope in strain-height curves, which is shown in Figure 16.

3.6.3. Direct Bond Specimens. For direct bond specimens, because the ultimate load of specimens with normal concrete is very small and axial strain obtained is limited, the strain of expansive concrete specimen (P-1) is analyzed only. In the case of $\mathrm{P}-1$, an almost uniform strain distribution is observed for the initial loading levels. However, when load increases to $5 \mathrm{kN}$, the strain increases markedly in the upper strain gauge, as shown in Figures 17 and 18. The final strain distribution along the height of FRP tube is also a polygonal line.

It is noted that the maximum strain of direct bond specimens is only about one-fifth of other two bond types, due to the poor bond stress between FRP tube and concrete. Because the bond stress is low, sliding failure would occur between FRP and concrete under a small load, leading to the stress and strain of FRP tube are very small. Therefore, direct bond type is not recommended in practical engineering. 


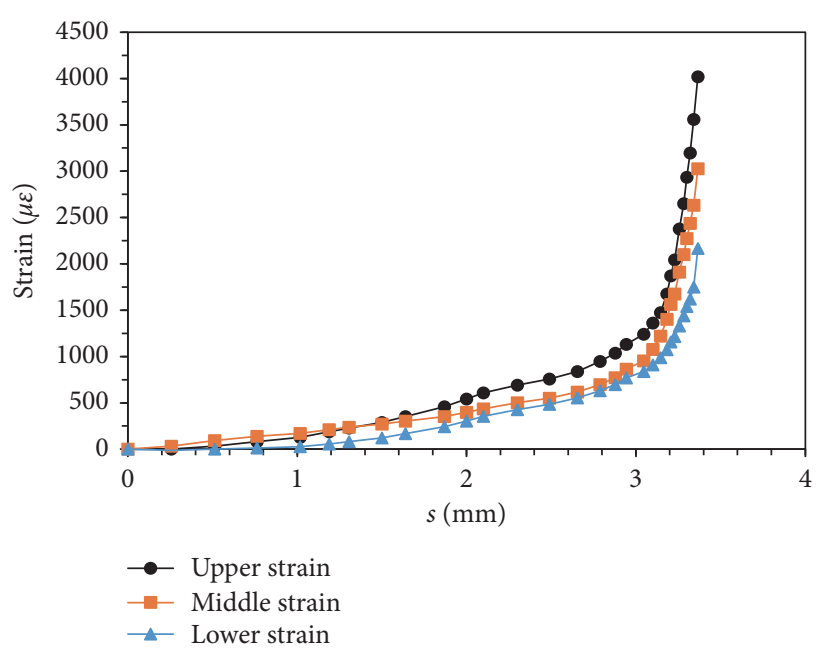

(a)

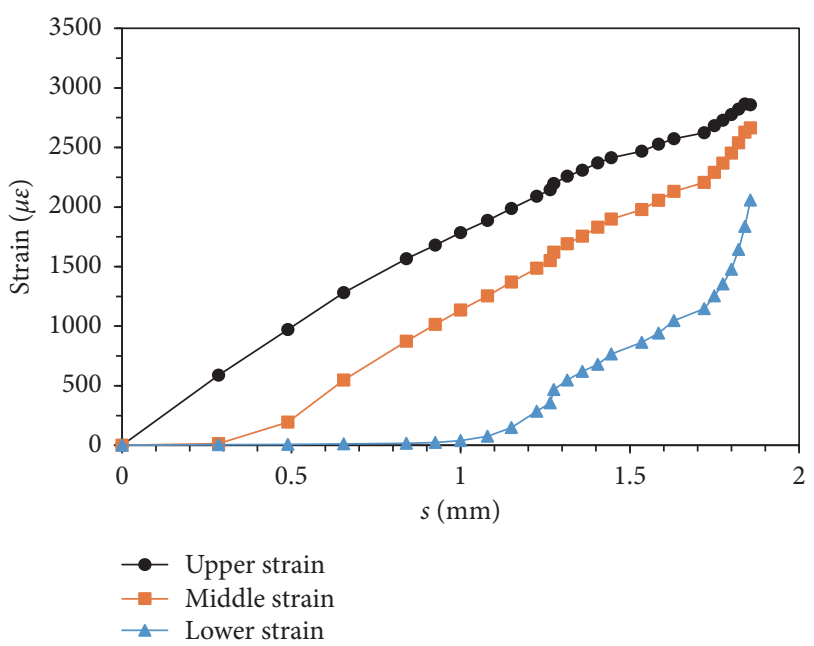

(b)

FIGURE 13: Strain-slip curves of specimens with internal threads. (a) 4-2. (b) P-2.

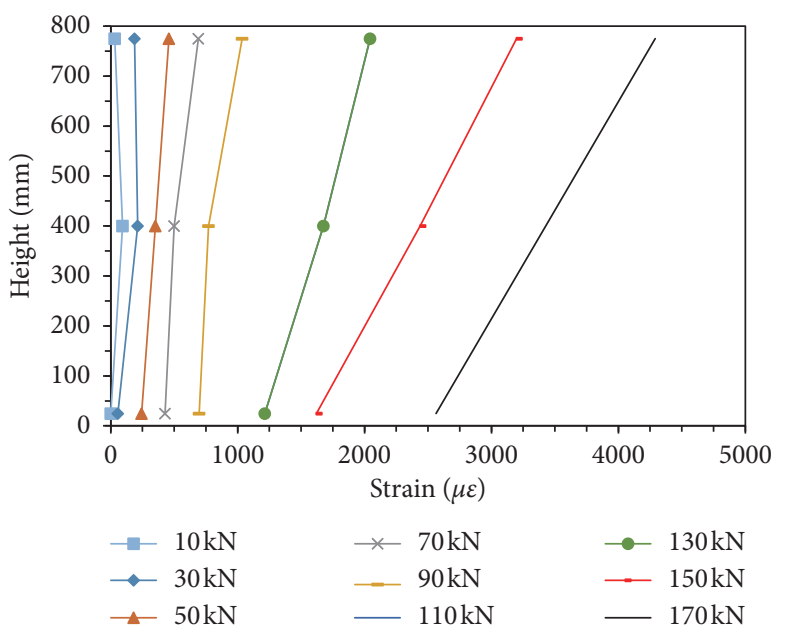

(a)

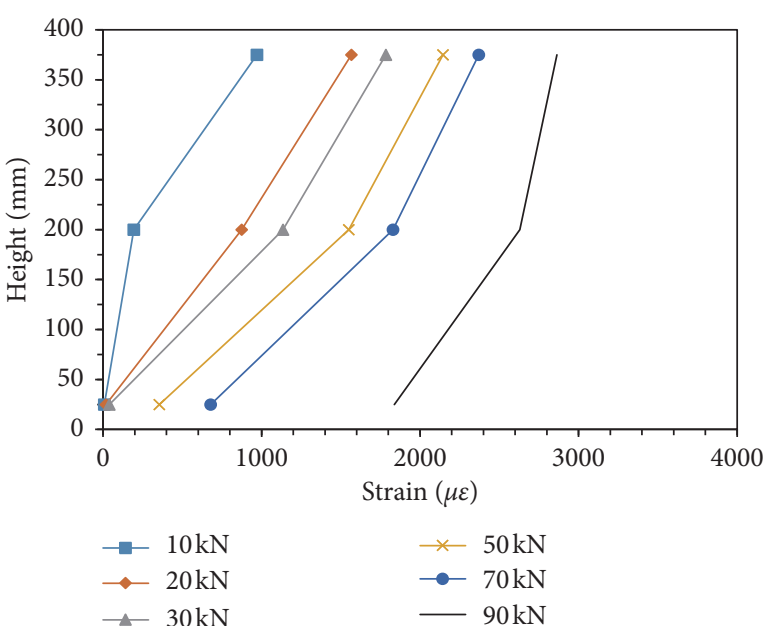

(b)

FIGURE 14: Strain height of FRP tube curves of specimens with internal threads. (a) 4-2. (b) P-2.

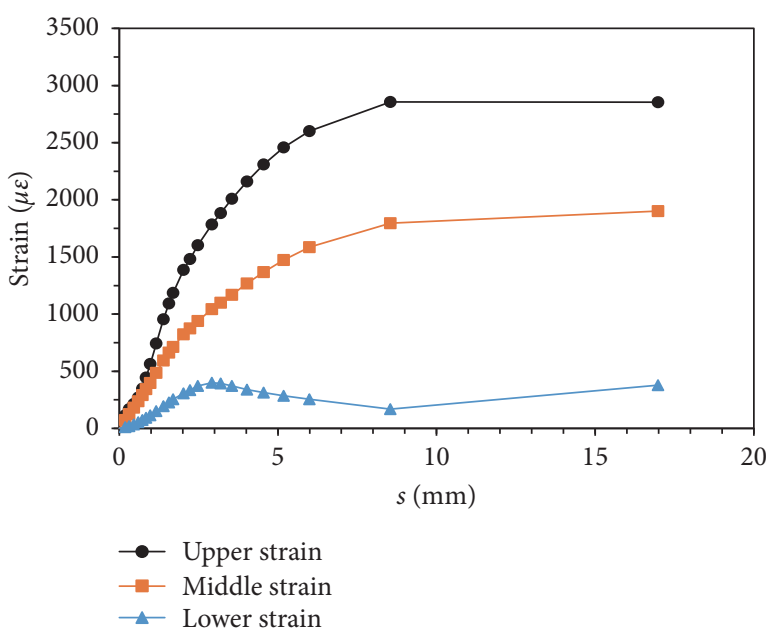

(a)

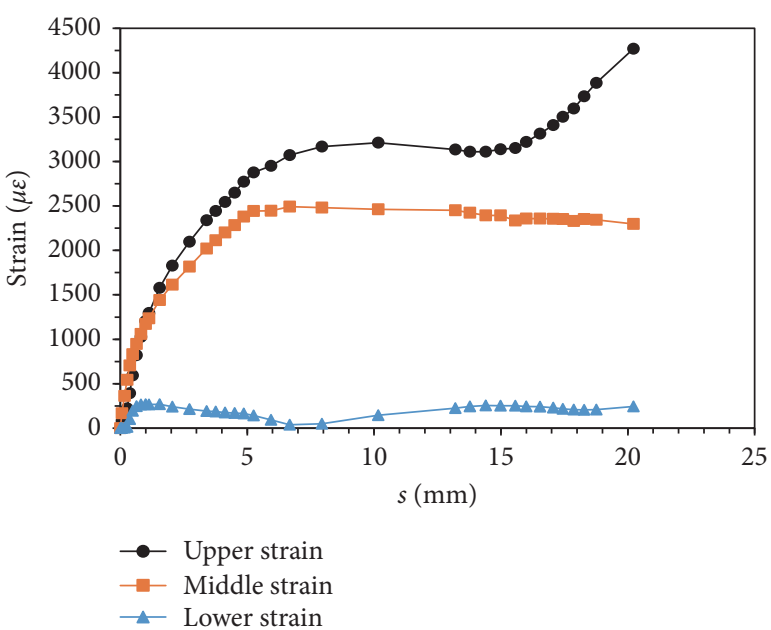

(b)

FIgURE 15: Strain-slip curves of specimens with shear connectors. (a) 4-3. (b) P-3. 


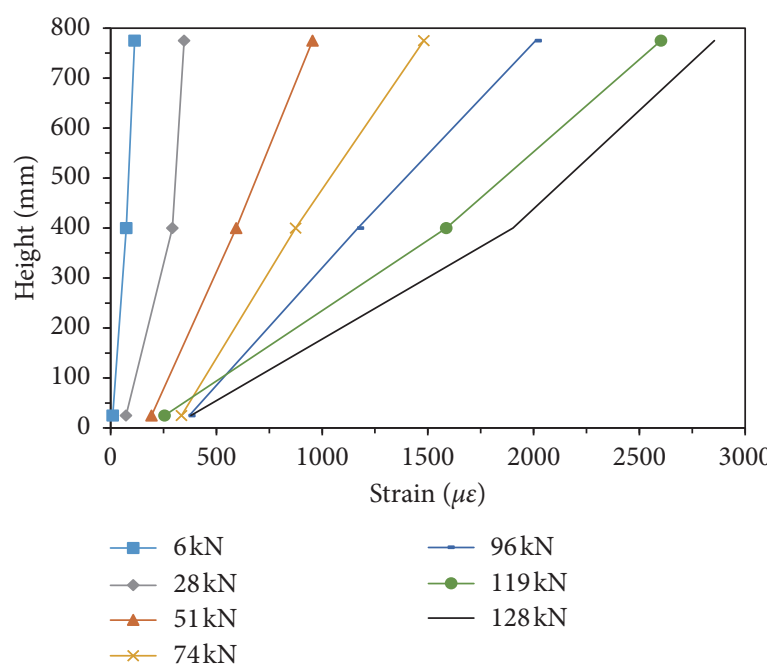

(a)

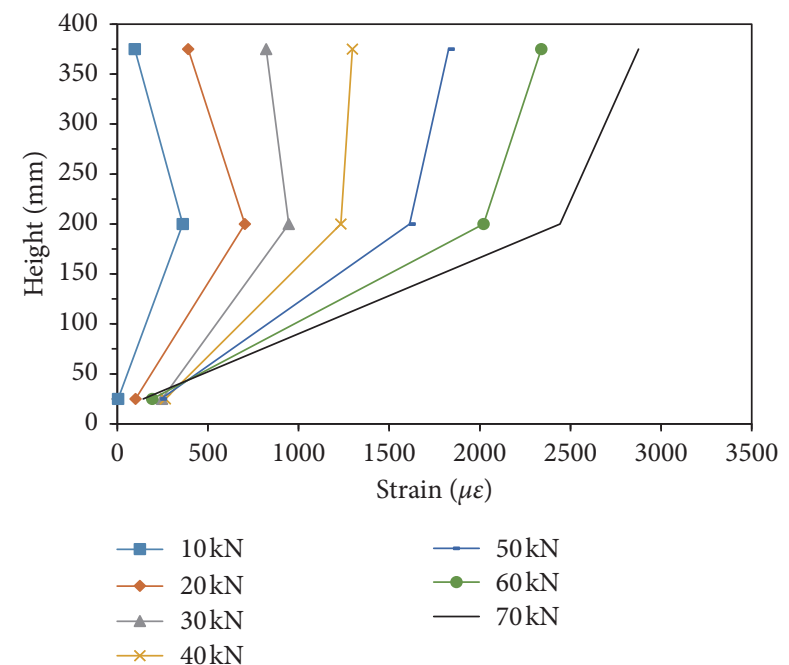

(b)

FIGURE 16: Strain height of FRP tube curves of specimens with shear connectors. (a) 4-3. (b) P-3.

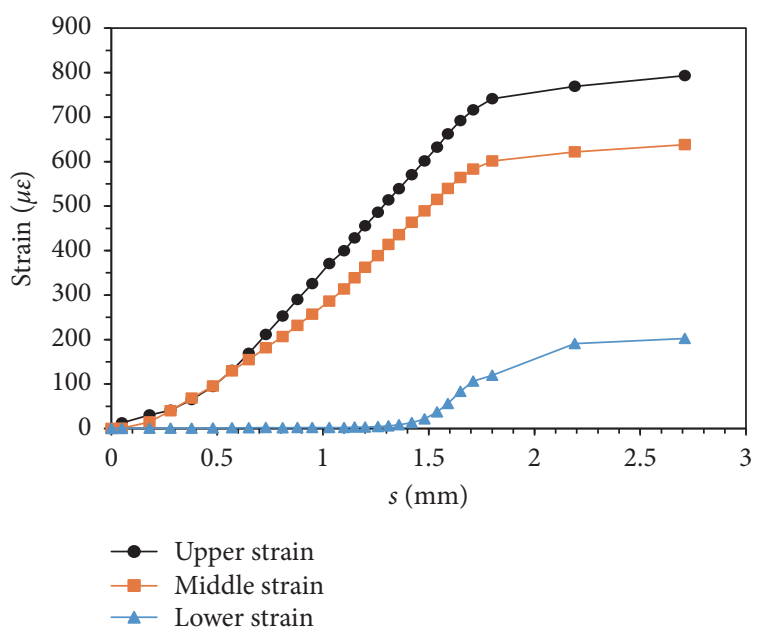

FIGURE 17: Strain-slip curves of direct bond specimens.

3.7. Simplified Bond-Slip Constitutive Models. Different bond types result in different $\tau-s$ curves, as discussed above. Because bond type is the most important factor, it is reasonable to establish the simplified bond-slip constitutive models according to bond type introduced in this paper.

3.7.1. Direct Bond Specimens. As seen from the test results of direct bond specimens in this paper, a typical $\tau-s$ curve for direct bond specimens is shown in Figure 19. As the load is applied, the ratio between $\tau$ and $s$ is approximately linear at first, and the interfacial bond behaves almost as an elastic interface with virtually a full recovery of slip if the load is removed. As soon as the chemical adhesion breaks, the curve is no longer linear, and the maximum $\tau$ appears. After $\tau_{u}, \tau$ decreased slightly and then remain constant as $s$ increases to a value that may range from two to ten times than $s_{u}$.

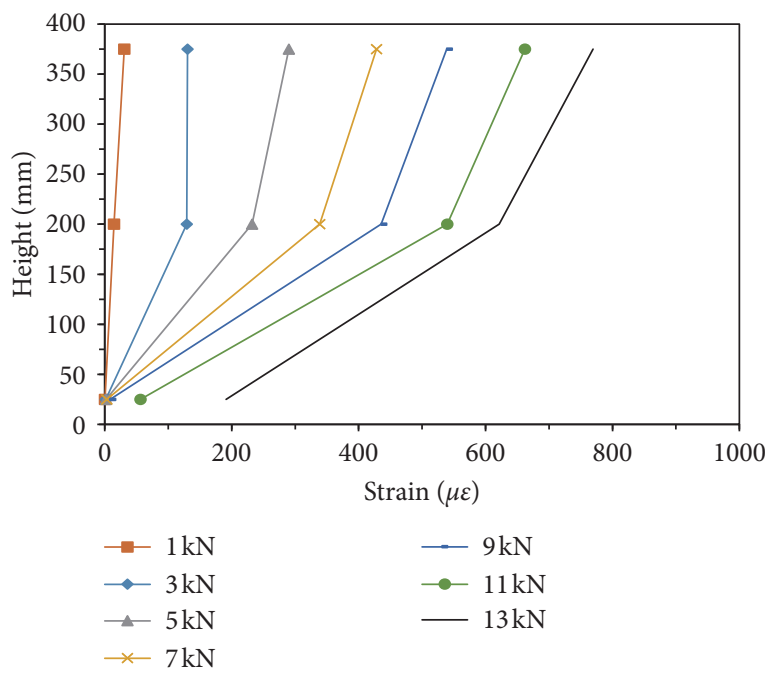

Figure 18: Strain-height curves of direct bond specimens.

As mentioned before, for direct bond specimens, the applied load is transmitted by chemical adhesion and friction between FRP tube and concrete. Because chemical adhesion is very small, the typical $\tau-s$ curve for direct bond specimens could be considered to be the transition from static friction to dynamic friction.

Thus, equation (2) could be used to describe the bondslip constitutive model of direct bond specimens.

$$
\begin{cases}\tau=a s^{2}+b s, & s \leq s_{u}, \\ \tau=\left(\frac{\tau_{r}-\tau_{u}}{s_{r}-s_{u}}\right)\left(s-s_{u}\right)+\tau_{u}, & s_{u}<s \leq s_{r}, \\ \tau=\tau_{r}, & s>s_{r},\end{cases}
$$

where $a$ and $b$ are coefficients, which should be generated by tests. 


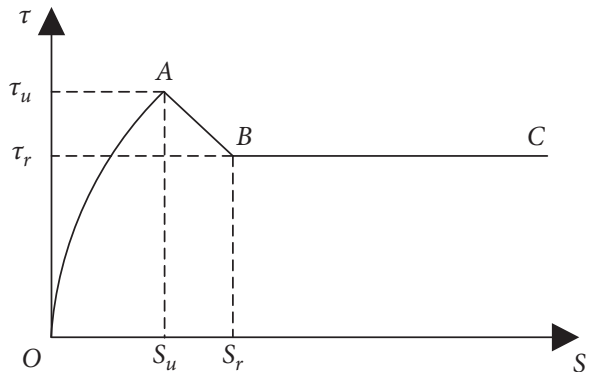

Figure 19: Simplified model of the $\tau-s$ curve of direct bond specimens.

It is easy to calculated that for $\mathrm{P}-1$, representing direct bond specimens, when $a=15$ and $b=5$, good agreements can be reached between the test results and results of equation (2), as shown in Figure 20.

3.7.2. Specimens with Internal Threads. The typical $\tau-s$ curve of specimens with internal threads is shown in Figure 21. It is clear that the $\tau-s$ curve of specimens with internal threads, which can be divided into three sections by point $A\left(\tau_{u} s_{u}\right)$ and point $B\left(\tau_{r} s_{r}\right)$, is approximately but not exactly the same as that of direct bond specimens.

The biggest difference is in the first section (from point $O$ to point $A$ ). For direct bond specimens, the curve slope is gradually decreasing, while for specimens with internal threads, the curve slope is gradually increasing. This difference is thought to be a result of the developing law of anchoring forces between threads and concrete. Anchoring force between threads and concrete accounts for a large proportion of shear stress, and the ratio of anchoring forces to $s$ increases as specimen approaches failure.

Similarly, equation (3) is a relatively good expression form of the $\tau-s$ curve of specimens with internal threads.

$$
\begin{cases}\tau=\gamma e^{s}-\gamma, & s \leq s_{u}, \\ \tau=\left(\frac{\tau_{r}-\tau_{u}}{s_{r}-s_{u}}\right)\left(s-s_{u}\right)+\tau_{u}, & s_{u}<s \leq s_{r}, \\ \tau=\tau_{r}, & s>s_{r} .\end{cases}
$$

In equation (3), $\gamma$ is the coefficient of the test parameters. Figure 22 shows the comparison between test results and theoretical results of $\mathrm{P}-2$, which represents specimens with internal threads. It is clear that although some errors exist between the results, relatively good agreements can be reached when $\gamma=75$.

3.7.3. Specimens with Shear Connectors. For all specimens with shear connectors tested, all $\tau-s$ curves obtained exhibit the same law: with the increase of $s, \tau$ becomes larger firstly and keeps steady after arriving at $\tau_{u}$. Because of the

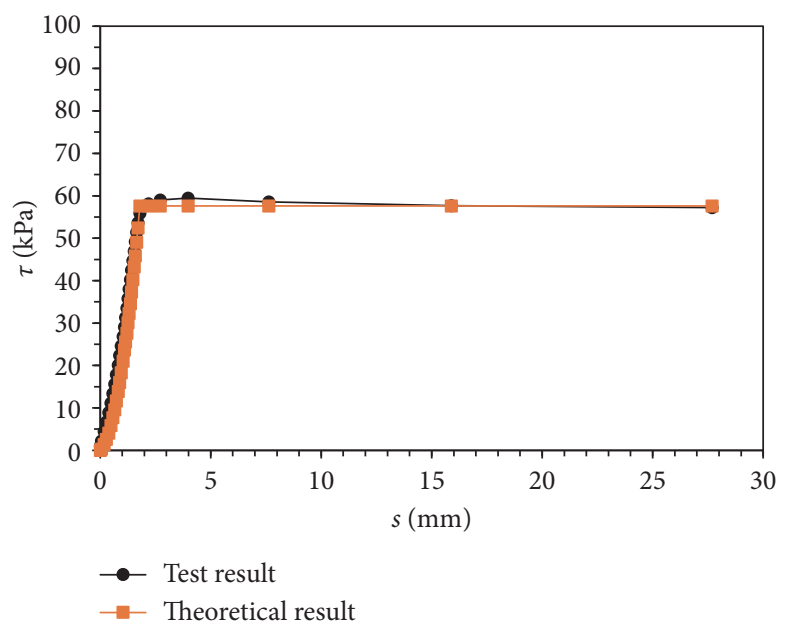

FIgURE 20: Comparison between test result and theoretical result of P-1.

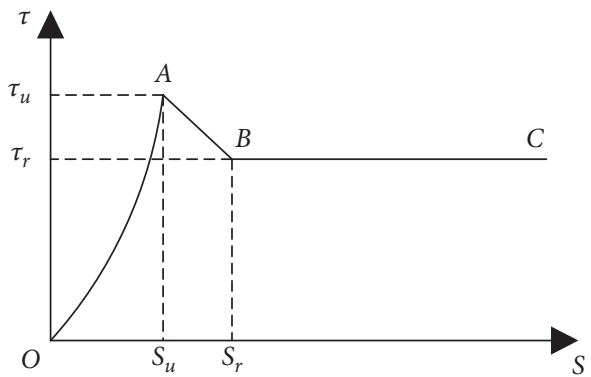

Figure 21: Simplified model for the $\tau-s$ curve of internal threads specimens.

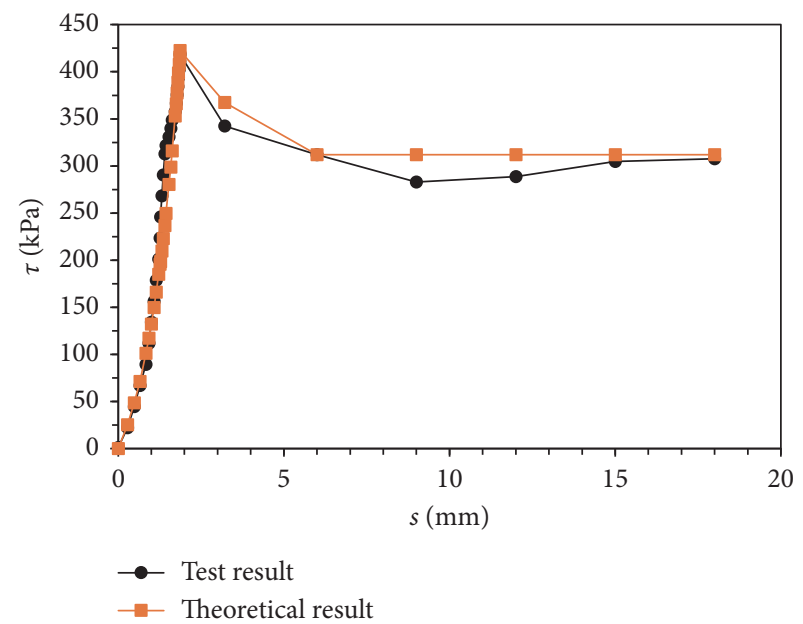

FIgURE 22: Comparison between test result and theoretical result of P-2.

persistence of anchoring force between shear connectors and concrete, the entire curve does not show a softening stage. Therefore, $\tau-s$ curves of specimens with shear connectors could be divided into two sections: an upward section and a steady section. A quadratic parabola and a straight line could be used to describe these two sections visually, and a 


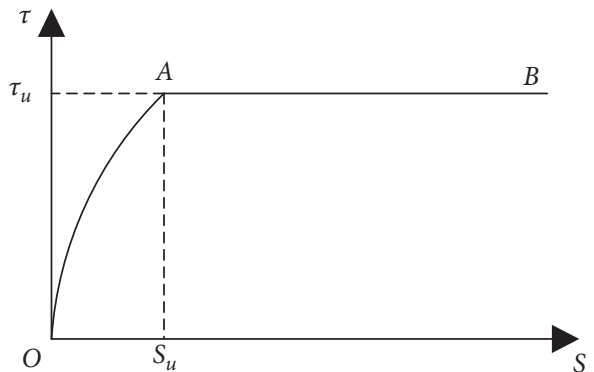

FIGURE 23: Simplified model for the $\tau-s$ curve of specimens with shear connectors.

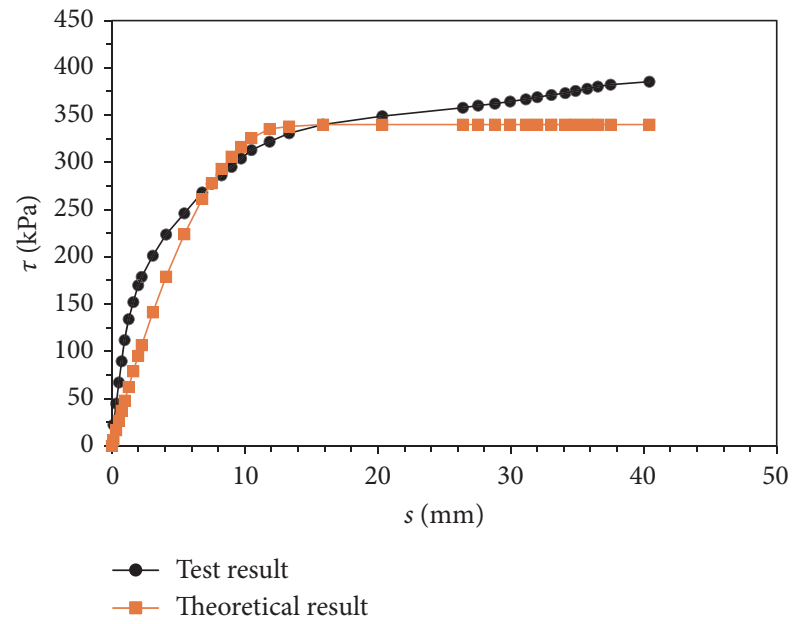

Figure 24: Comparison between test results and theoretical results of P-3.

simplified bond-slip constitutive model of specimens with shear connectors could be expressed as Figure 23 and equation (4).

$$
\begin{cases}\tau=a s^{2}+b s, & s \leq s_{u}, \\ \tau=\tau_{u}, & s>s_{u},\end{cases}
$$

where $a$ and $b$ are coefficients.

As shown in Figure 24, comparison between test results and theoretical results of P-3 illustrates that when $a=-2$ and $b=52$, results of equation (4) are very close to the test results. Although ultimate bond stress of equation (4) is smaller than the test result, it is beneficial to ensure the safety of FRPconfined concrete piles.

\section{Conclusions and Recommendations}

The following conclusions could be drawn based on pushout tests of twenty-nine specimens and the analysis of axial strain and simplified bond-slip constitutive models of concrete-filled FRP-composite piles:

The bond type, which determines the $\tau-s$ curve and failure model, is the most important factor influencing bond behavior between the FRP tube and concrete.

The slenderness ratio of FRP tube has little effect on bond behavior of all tests, leading to no obvious correlation between bond stress and slenderness ratio, which could be observed.

Bond stress of specimens with internal threads increases monotonically with decrease in the radius-thickness ratio because a smaller radius-thickness ratio could provide a better hoop constraint, while for specimens with shear connectors, bond stress is not directly related to radiusthickness ratio.

High-strength concrete is advantageous for bond behavior because a higher concrete strength results in an interfacial cohesion between FRP tube and concrete.

Bond behavior improves significantly after substituting expansive concrete for normal concrete for all specimens; compared with the improvement of concrete strength, the use of expansive concrete is more efficient and the bond stress has a greater increase.

The axial strain distribution of all FRP tubes demonstrated the following rules: the upper strain is greater than the middle strain, which is larger than the lower strain; but for normal concrete specimens, the strains are linearly distributed with height, while for expansive concrete specimens, the distribution curves are polygonal lines.

The simplified bond-slip constitutive models based on test results are simpler and more practical; however, their coefficients should be generated by tests.

\section{Data Availability}

The experimental data used to support the findings of this study are available from the first author upon request. The e-mail of first author is 230159416@seu.edu.cn.

\section{Conflicts of Interest}

The authors declare that they have no conflicts of interest.

\section{Acknowledgments}

This work was supported by the National Key Research Program of China (Grant no. 2017YEC0703408) and the National Natural Science Foundation of China (Grant no. 51478109).

\section{References}

[1] C. Viggiani, A. Mandolini, and G. Russo, Piles and Pile Foundations, Spon Press, London, UK, 2012.

[2] E. Guades, T. Aravinthan, M. Islam, and A. Manalo, "A review on the driving performance of FRP composite piles," Composite Structures, vol. 94, no. 6, pp. 1932-1942, 2012.

[3] M. G. Iskander, S. Hanna, and A. Stachula, "Driveability of FRP composite piling," Journal of Geotechnical and Geoenvironmental Engineering, vol. 127, no. 2, pp. 169-176, 2001.

[4] A. Mirmiran and M. Shahawy, "A new concrete-filled hollow FRP composite column," Composites Part B: Engineering, vol. 27, no. 3-4, pp. 263-268, 1996.

[5] P. Sadeghian, Y. C. Lai, and A. Fam, "Testing and modeling of a new moment connection of concrete-filled FRP tubes to footings under monotonic and cyclic loadings," Journal of Composites for Construction, vol. 15, no. 4, pp. 653-662, 2011. 
[6] Z. Achillides and K. Pilakoutas, "Bond Behavior of Fiber reinforced polymer bars under direct pullout conditions," Journal of Composites for Construction, vol. 8, no. 2, pp. 173-181, 2004.

[7] J. Larralde and R. Silva-Rodriguez, "Bond and slip of FRP rebars in concrete," Journal of Materials in Civil Engineering, vol. 5, no. 1, pp. 30-40, 1993.

[8] Q.-D. Hao, Y.-L. Wang, Z.-C. Zhang, and J.-P. Ou, "Bond strength improvement of GFRP rebars with different rib geometries," Journal of Zhejiang University-Science A, vol. 8, no. 9, pp. 1356-1365, 2007.

[9] C. Pellegrino, D. Tinazzi, and C. Modena, "Experimental study on bond behavior between concrete and FRP reinforcement," Journal of Composites for Construction, vol. 12, no. 2, pp. 180-189, 2008.

[10] M. Baena, L. Torres, A. Turon, and C. Barris, "Experimental study of bond behaviour between concrete and FRP bars using a pull-out test," Composites Part B: Engineering, vol. 40, no. 8, pp. 784-797, 2009.

[11] H. M. Diab and O. A. Farghal, "Bond strength and effective bond length of FRP sheets/plates bonded to concrete considering the type of adhesive layer," Composites Part B: Engineering, vol. 58, no. 3, pp. 618-624, 2014.

[12] L. Lovinella, A. Prota, and C. Mazzotti, "Influence of surface roughness on the bond of FRP laminates to concrete," Construction and Building Materials, vol. 40, pp. 533-542, 2013.

[13] J. Chen and N. Chouw, "Effect of the interface condition on the bond between flax FRP tube and coconut fibre reinforced concrete composites," Construction and Building Materials, vol. 167, pp. 597-604, 2018.

[14] A. Katz, "Bond mechanism of FRP rebars to concrete," Materials and Structures, vol. 32, no. 10, pp. 761-768, 1999.

[15] A. Katz, N. Berman, and L. C. Bank, "Effect of high temperature on bond strength of FRP rebars," Journal of Composites for Construction, vol. 3, no. 2, pp. 73-81, 1999.

[16] A. Katz, "Bond to concrete of FRP rebars after cyclic loading," Journal of Composites for Construction, vol. 4, no. 3, pp. 137-144, 2000.

[17] G. Li, S. Torres, W. Alaywan, and C. Abadie, "Experimental study of FRP tube-encased concrete columns," Journal of Composite Materials, vol. 39, no. 13, pp. 1131-1145, 2005.

[18] J.-G. Dai, H. Yokota, M. Iwanami, and E. Kato, "Experimental investigation of the influence of moisture on the bond behavior of FRP to concrete interfaces," Journal of Composites for Construction, vol. 14, no. 6, pp. 834-844, 2010.

[19] X. H. Zheng, P. Y. Huang, G. M. Chen, and X. M. Tan, "Fatigue behavior of FRP-concrete bond under hygrothermal environment," Construction and Building Materials, vol. 95, pp. 898-909, 2015.

[20] M. Savoia, B. Ferracuti, and L. Vincenzi, "Inverse analysis for the calibration of FRP-concrete interface law," Advances in Structural Engineering, vol. 12, no. 5, pp. 613-625, 2009.

[21] R. Z. Al-Rousan, "Empirical and NLFEA prediction of bondslip behavior between DSSF concrete and anchored CFRP composites," Construction and Building Materials, vol. 169, pp. 530-542, 2018.

[22] Y. Tao and J. F. Chen, "Concrete damage plasticity model for modelling FRP-to-concrete bond behavior," Journal of Composites for Construction, vol. 19, no. 1, Article ID 04010326, 2015.

[23] X. Li, J.-F. Chen, Y. Lu, and Z. Yang, "Modelling static and dynamic FRP-concrete bond behavior using a local concrete damage model," Advances in Structural Engineering, vol. 18, no. 1, pp. 45-58, 2015.

[24] P. Neto, J. Alfaiate, D. Dias-da-Costa, and J. Vinagre, "Mixedmode fracture and load misalignment on the assessment of FRP-concrete bond connections," Composite Structures, vol. 135, pp. 49-60, 2016.

[25] R. Lopez-Anido, A. P. Michael, and T. C. Sandford, "Fibre reinforced polymer composite-wood pile interface characterization by push-out tests," Journal of Composites for Construction, vol. 8, no. 4, pp. 360-368, 2004.

[26] P. Colajanni, L. La Mendola, and A. Monaco, "Stress transfer mechanism investigation in hybrid steel trussed-concrete beams by push-out tests," Journal of Constructional Steel Research, vol. 95, pp. 56-70, 2014.

[27] L. Zhang, C. Ren, C. Zhou, H. Xu, and X. Jin, "Single fiber push-out characterization of interfacial mechanical properties in unidirectional CVI-C/SiC composites by the nano-indentation technique," Applied Surface Science, vol. 357, pp. 1427-1433, 2015.

[28] Y. Yang, H. Biscaia, C. Chastre, and M. A. G. Silva, "Bond characteristics of CFRP-to-steel joints," Journal of Constructional Steel Research, vol. 138, pp. 401-419, 2017.

[29] L. Yan, N. Chouw, and K. Jayaraman, "Effect of column parameters on flax FRP confined coir fibre reinforced concrete," Construction and Building Materials, vol. 55, pp. 299-312, 2014.

[30] H. C. Biscaia, C. Chastre, and M. A. G. Silva, "Bond-slip model for FRP-to-concrete bonded joints under external compression," Composites Part B: Engineering, vol. 80, pp. 246-259, 2015. 